\title{
Distribuição e origem dos minerais detríticos pesados das areias praiais holocênicas do litoral norte do Rio Grande do Sul
}

\author{
Carla Ennes de Barros ${ }^{1}$, Lauro V. S. Nardi ${ }^{1}$, Sergio R. Dillenburg ${ }^{1}$, Ricardo Baitelli ${ }^{1}$ \& \\ Beatriz, Appel Dehnhardt ${ }^{1}$
}

\begin{abstract}
Resumo Este trabalho discute fontes primárias dos minerais pesados detríticos das areias praias holocênicas do sul do Brasil, baseado nas composições minerais. Ao longo do litoral norte do Rio Grande do Sul, foram coletadas 5 amostras de areia a cada $40 \mathrm{~km}$. Os elementos traços foram analisados por LA-ICP-MS e os elementos maiores por microssonda e microscopia eletrônica. A composição dos piroxênios indica fontes de granulitos e rochas básicas pós-colisionais. Rochas metapelíticas de alto grau e anfibolitos são fontes importantes indicadas pela presença de estaurolita, rutilo, silicatos de alumínio, grossulária, zoisita, turmalinas cálcicas e cumingtonita presentes em todas amostras. Granitóides do tipo A são fontes evidenciadas pelos zircões com alto teor de $\mathrm{Nb}$ e ETR, razões $\mathrm{Nb} / \mathrm{Ta}>20$ e anfibólios com razão $\mathrm{Fe} /(\mathrm{Fe}+\mathrm{Mg})>0,9$. Granitóides peraluminosos estão representados pela granada rica em espessartina e turmalina rica em ferro, enquanto, granitóides shoshoníticos e subalcalinos médio e alto-K são sugeridos pelo epidoto magmático, titanita, anfibólios cálcicos com moderadas $\mathrm{Fe} /(\mathrm{Fe}+\mathrm{Mg})$ e zircões com $\mathrm{Th} / \mathrm{U}=0,3-0,5 \mathrm{e} \mathrm{Nb} / \mathrm{Ta}=5-15$. Anfibólios magnesianos indicam fontes ultramáficas. Rochas hidrotermalizadas são também constituintes das áreas, apontadas por turmalinas litiníferas, actinolita e epidoto hidrotermal. A homogeneidade dos tipos e abundâncias dos minerais detríticos em todas amostras do litoral norte indicam uma área fonte comum para esses sedimentos praiais. O extremo nordeste do Batólito Pelotas é a provável área fonte da região. Este estudo demonstra que a química de minerais detritais, incluindo elementos traços em zircões, pode produzir informações detalhadas quanto à área fonte primária, constituindo poderosa ferramenta neste tipo de investigação.
\end{abstract}

Palavras-chave: proveniência, química mineral, minerais detríticos, planície costeira do Rio Grande do Sul, sedimentos praiais.

\begin{abstract}
Distribution and origin of heavy-detrital minerals in the Holocene beach sands from northern coast of Rio Grande do Sul, southernmost Brazil. This study discusses the primary sources of detrital minerals of the Holocenic beach sediments from southern Brazil, based mainly on their chemical composition. Five samples of beach sand were collected at each $40 \mathrm{~km}$ along the northern littoral of southernmost Brazil. Trace elements were determined by LA-ICP-MS and major elements by microprobe and electron microscopy. Pyroxene compositions indicate the contribution of granulites and post-collisional basic rocks. High-grade metapelitic rocks and amphibolites are important sources suggested by staroulite, rutile, aluminium silicates, almandine, grossular, zoisite, Ca-rich tourmaline, and commingtonite, identified in all samples. A-type granitoids in the source area are indicated by zircons with high $\mathrm{Nb}$ and ETR contents, $\mathrm{Nb} / \mathrm{Ta}$ ratios $>20$, and amphiboles with $\mathrm{Fe} /(\mathrm{Fe}+\mathrm{Mg})>0.9$. Peraluminous granitoids are indicated by $\mathrm{Mn}$-rich garnet and Fe-rich tourmaline, whilst the occcurrence of shoshonitic and medium to high-K subalkaline granitoids is pointed out by magmatic epidote, titanite, calcic amphiboles with moderate $\mathrm{Fe} /(\mathrm{Fe}+\mathrm{Mg})$ ratios and zircons with $\mathrm{Th} / \mathrm{U}=0.3-0.5$ and $\mathrm{Nb} / \mathrm{Ta}=5-15$. Magnesian amphiboles indicate ultramafic sources. Hydrothermal products are also indicated in the primary sources by Li-rich tourmaline, actinolite, and hydrothermal epidotes. The homogeneity of abundance and typology of detrital minerals in the northern littoral indicate a common source for the studied sediments. The northeastern part of the Pelotas Batholith, is the probable source region. This study confirms that the chemistry of detrital minerals, including trace elements in zircons, can yield detailed and accurate information about their primary source, and so be of high relevance for provenance studies.
\end{abstract}

Keywords: provenance, mineral chemistry, detrital minerals, coastal plain of Rio Grande do Sul, beach sediments.

INTRODUÇÃO Os primeiros trabalhos referentes à presença de minerais pesados, ao longo da planície costeira do Rio Grande do Sul, foram os de Delaney (1965) e Martins (1967). Abreu (1973) descreveu a existência de areias ilmeníticas na área de Santa Vitória do Palmar. Po- merancblum \& Costa (1972) estudando os minerais pesados da plataforma continental da região do Rio Grande até o Chuí, determinaram que estes sedimentos da região interna da plataforma provinham de rochas metamórficas e os da região externa principalmente de rochas básicas.

1 - Universidade Federal do Rio Grande do Sul, Instituto de Geociências, Centro de Estudos de Geologia Costeira e Oceânica, Porto Alegre (RS), Brasil. E-mail: carla.barros@ufrgs.br; lauro.nardi@ufrgs.br; sergio.dillenburg@ufrgs.br; ricardo.baitelli@ufrgs.br e beatriz. dehnhardt@ufrgs.br 
Martins da Silva (1979) estudou a origem dos minerais pesados presentes nas areias de praia entre Rio Grande e Chuí, concluindo que esta assembléia mineralógica teve como área fonte primária as rochas do Escudo Sul-rio-grandense e as basálticas da formação Serra Geral.

Villwock et al. (1979), estudando as areias negras ao longo da costa do Rio Grande do Sul, propuseram que estes sedimentos são derivados de rochas metamórficas e ígneas do Escudo Sul-rio-grandense e de formações sedimentares e cobertura vulcânica de idade Paleozóica a Mesozóica. Loss e Dehnhardt (1983) confirmaram esta proposição a partir de estudos da concentração das areias negras.

Munaro (1994) estudou os minerais pesados da região de Bojuru (litoral médio do Rio Grande do Sul) e sugere fonte primordial derivada do leque deltáico associado à paleodrenagem do Rio Camaquã na plataforma interna, cujos sedimentos foram retrabalhados e redepositados no decorrer das variações eustáticas posteriores. Também propõe que os minerais de interesse econômico (ilmenita, leucoxênio, rutilo, zircão e cianita) provêem das rochas do Escudo Sul-rio-grandense, enquanto os minerais pesados derivados dos basaltos da Formação Serra Geral são a magnetita e titano-magnetita.

Dillenburg et al. (2004) propõem que a formação do placer de Bojuru se dá pelo retrabalhamento dos depósitos da planície costeira existentes e pela retenção, em Bojuru, de parte dos minerais pesados transportados pelas correntes costeiras (deriva litorânea).

Tomazelli (1978) estudando os minerais pesados da plataforma continental classifica-os em quatro províncias diferentes: Rio-grandense interna que apresenta como área fonte o Escudo Sul-rio-grandense; $\mathrm{Pa}$ tos cuja fonte seriam os rios que deságuam na lagoa dos Patos; Rio-grandense externa da qual a fonte seria de rios provenientes do continente (escudo e basalto) em épocas de nível do mar mais baixo e Platina originada pelo rio de La Plata em níveis de mar mais baixo.

Corrêa et al. (2001) estudaram os minerais pesados nos sedimentos de fundo da plataforma continental sul-brasileira e baseado na composição mineralógica propõem como fontes rochas metamórficas e basálticas, sedimentos pampeanos-patagônicos e rochas do Escudo sul-rio-grandense e uruguaio.

Ayup-Zouain et al. (2001 e 2002), com base na identificação dos minerais pesados presentes nos sedimentos superficais da plataforma continental adjacente à Planicie Costeira do Rio Grande do Sul, sugerem quatro fontes de proveniência destes minerais: sedimentos de origem Pampeano-patagônico (na parte mais a sul), sedimentos Guaraní formados por sistemas de drenagem do setor central do Escudo Sul-rio-grandense em direção aos basaltos para o norte, sedimentos Gaúchos formados por rochas metamórficas e de metamorfismo de contato, e sedimentos Platenses derivados das rochas do Escudo Sul-rio-grandense e Uruguaio a partir de paleodrenagem continental adjacente ao estuário do Plata.

A proveniência destes minerais pesados foi estudada no passado, mas somente conclusões muito gerais foram apresentadas, sugerindo a origem destes mi- nerais com rochas ígneas, metamórficas e sedimentares que se encontram nas terras altas adjacentes (Martins da Silva 1979, Villwock et al. 1979, Loss \& Dehnhardt 1983). Os estudos de proveniência no mundo nos últimos anos são focados na química dos minerais pesados. Em muitos destes trabalhos, as propriedades químicas do zircão tem sido consideradas como uma promissora ferramenta para estudos de proveniência. Belousova et al. (2002), Rubatto (2002), Hoskin \& Schaltegger (2003), Gehrels et al. (2003).

A COSTA DO RIO GRANDE DO SUL A margem continental do sul do Brasil constitui um limite de placa formada nos primórdios do Cretáceo. No Rio Grande do Sul (entre $29^{\circ}$ e $34^{\circ}$ de latitude sul) a deposição de uma grande quantidade de sedimentos clásticos pósrift, gerou uma ampla plataforma continental (100 a 200 $\mathrm{km})$, rasa $(100 \mathrm{a} 140 \mathrm{~m})$ e de mergulho suave $\left(0,03^{\circ} \mathrm{a}\right.$ $\left.0,08^{\circ}\right)$. Registros sísmicos da parte superior do talude revelaram uma espessura sedimentar de, no mínimo, $10 \mathrm{~km}$ (Fontana 1990). Na parte continental, durante o Quaternário, formou-se uma planície costeira de baixo relevo pela justaposição de depósitos sedimentares de quatro sistemas do tipo barreira-laguna designados por Villwock et al. (1986) de I (mais antigo) a IV (mais novo). A planície costeira varia de 20 a $80 \mathrm{~km}$ de largura, bordejada por depósitos de leques aluviais e altos topográficos rochosos (Fig. 1). O clima é úmido com temperaturas médias de $26^{\circ}$ no verão e $12^{\circ}$ no inverno. As precipitações oscilam entre 1000 e $1500 \mathrm{~mm}$ sendo uniformemente distribuídas por todo o ano.

$\mathrm{O}$ extremo sul do Brasil é sujeito a regime de ondas do tipo swell, geradas nas latitudes sul e também por ondas do tipo sea (vagas) formadas pela ação do vento nordeste. A altura média das ondas é de $1,5 \mathrm{~m}$ medida entre as profundidades de 15 a $20 \mathrm{~m}$ (Motta inédito). O transporte litorâneo é para Norte. Apresenta ainda, regimes de micromarés semidiurnas com variação de apenas $0,5 \mathrm{~m}$. Atualmente, as praias do Rio Grande do Sul recebem muito pouca areia do continente, porque a maior parte do aporte sedimentar feito pelos poucos riachos e rios que drenam a costa é retido nas lagoas e outros ambientes da planície costeira (Tomazelli et al. 1998). Devido a mudanças na orientação da linha de costa, e na morfologia interna e no gradiente da plataforma continental interna, as praias do Rio Grande do Sul são expostas a diferentes graus de energia de ondas (Dillenburg et al 2004).

\section{AMOSTRAGEM E PROCEDIMENTOS ANALÍ-} TICOS Em abril de 2002, ao longo do litoral norte, numa extensão de $160 \mathrm{~km}$, foram coletadas 5 amostras de areia, uma a cada $40 \mathrm{~km}$, em segmento costeiro reconhecidamente homogêneo, do ponto de vista da composição textural e mineralógica das areias praiais do Rio Grande do Sul, sendo consideradas bastante satisfatórias. Estas amostras, com em torno de $1 \mathrm{~kg}$, foram retiradas da face de praia. Em laboratório, foram lavadas, para a retirada do sal, secas em estufa a $50^{\circ} \mathrm{C}$ e, posteriomente, quarteadas e reduzidas a sub-amostras 


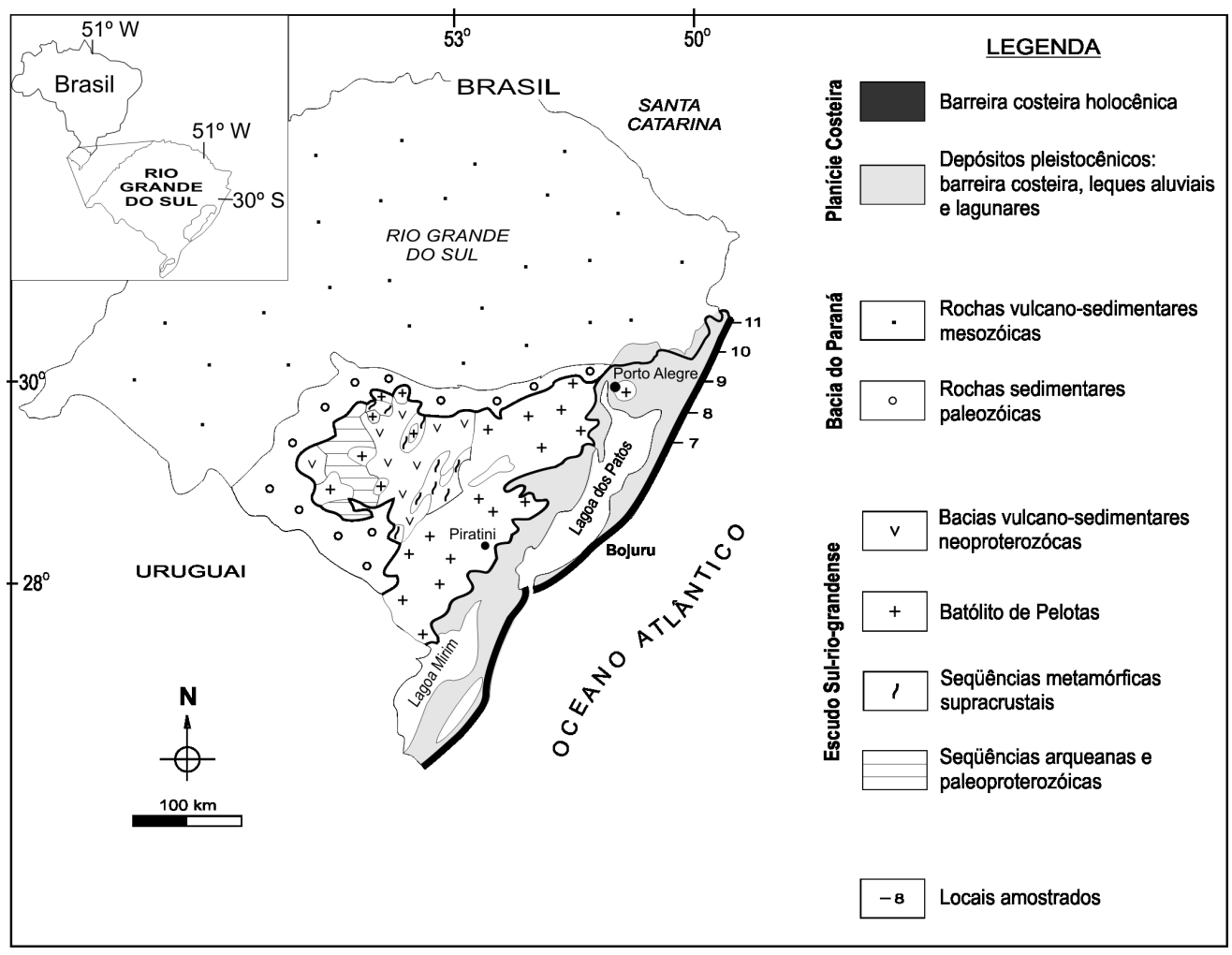

Figura 1 - Mapa Geológico da Planície Costeira do Rio Grande do Sul e a localização das amostras.

com 70-90g. A parte quarteada foi separada em intervalo de $1 \varphi$. Cada intervalo foi pesado em balança de precisão e submetido à separação dos minerais pesados com bromorfómio $\left(\mathrm{d}=2,83 \mathrm{~g} / \mathrm{cm}^{3}\right)$. A maior quantidade de minerais pesados encontra-se no intervalo $\varphi=4-3$ (areia muito fina), razão pela qual este foi o intervalo analisado. Os minerais magnéticos (magnetita) foram separados com um ímã de mão. A fração menos magnética foi levada ao separador isomagnético Frantz para a separação de frações em diferentes intervalos de susceptibilidade magnética, utilizando amperagens diversas. Em cada intervalo, em lupa binocular, foram descritos e separados manualmente os diferentes minerais. As suítes de minerais selecionados foram preparadas em pastilhas para análises químicas por microssonda eletrônica, visando caracterizar as espécies minerais presentes e suas variações composicionais.

Os minerais estudados foram: zircão, piroxênio, anfibólio, epidoto, turmalina e granada.

O zircão foi estudado detalhadamente por Barros et al. (submetido). Nos demais minerais (Tab. 1), as análises foram feitas para os principais componentes químicos dos minerais com microssonda eletrônica Cameca SX50 - do Centro de Pesquisas de Petrologia e Geoquímica - CPGQ da Universidade Federal do Rio Grande do Sul (UFRGS) e do Instituto de Geociências da Universidade de São Paulo.

Tabela 1 - Número de grãos dos diferentes minerais em cada amostra.

\begin{tabular}{l|c|c|c|c|c|c}
\hline & anfibólio & piroxênio & \multicolumn{2}{|c|}{ epidoto } & granada & turmalina \\
\hline \multirow{2}{*}{$\begin{array}{l}\text { Total de grãos } \\
\text { analisados }\end{array}$} & 115 & 57 & epidotos & zoisita & \multirow{2}{*}{39} & 50 \\
\cline { 4 - 6 } & & & 108 & 27 & & 17 \\
\hline Amostra 11 & 40 & 26 & 41 & 12 & 25 \\
\hline Amostra 10 & 14 & 8 & 20 & - & 13 & 4 \\
\hline Amostra 9 & 31 & 13 & 22 & 1 & 3 & 2 \\
\hline Amostra 8 & 24 & 9 & 10 & 2 & 5 & 3 \\
\hline Amostra 7 & 6 & 1 & 15 & 12 & 1 & 16 \\
\hline
\end{tabular}


DISTRIBUIÇÃO DA VARIAÇÃO GRANULOMÉTRICA DOS MINERAIS LEVES E PESADOS NAS AMOSTRAS ESTUDADAS Nas amostras estudadas predominam sedimentos de granulação correspondente a areia (Tab. 2). A maior percentagem de peso de minerais pesados (MP) ocorre no intervalo de areia muito fina $(\mathrm{AMF}=4-3 \varphi)$, e a dos minerais leves predomina no intervalo da Areia Fina $(\mathrm{AF}=3-2 \varphi)$. A mineralogia detrítica pesada é composta de: zircão, turmalina, rutilo, titanita, ilmenita, magnetita, epidoto, sillimanita, cianita, estaurolita, granada, anfibólio, piroxênio e apatita e a mineralogia leve por quartzo, feldspato potássico, plagioclásio e material orgânico como carapaças de foraminíferos.

Nas amostras estudadas, a fração areia fina é a predominante para os minerais leves (Tab. 2). A AMF varia de $33,68 \%$ na amostra 11 a $14,05 \%$ na amostra 7 ; a AF varia de $78,62 \%$ na amostra 7 a $63,67 \%$ na amostra 9 e a areia média (AM) varia de $6,86 \%$ na amostra 7 a $0,45 \%$ na amostra 11 .

Os minerais pesados ocorrem em teores baixos e somente são encontrados nas frações areias fina e muito fina (Tab. 2), sendo predominantes nesta última. $\mathrm{Na}$ fração areia fina as concentrações são de $0,01 \%$, enquanto na fração AMF variam de $0,11 \%$ a $0,59 \%$.

MINERALOGIA E VARIAÇ̃̃O MODAL DOS MINERAIS PESADOS NA FRAÇÃO GRANULOMÉTRICA DE AREIA MUITO FINA DAS AMOSTRAS ANALISADAS A mineralogia pesada é composta de: zircão, turmalina, rutilo, titanita, ilmenita, magnetita, epidoto, sillimanita, cianita, estaurolita, granada, anfibólio, piroxênio e apatita.

Os óxidos de ferro e titânio (magnetita e ilmenita ) são os minerais detríticos pesados mais abundantes nas amostras estudadas. Apresentam um maior enriquecimento relativo na amostra coletada no centro da área (amostra 9) com 33\% de minerais pesados na fração areia muito fina; e, no restante da área, variam de 21 a 26\%. (Tab. 3). A abundância dos demais minerais detríticos pesados é listada na tabela 3.

A distribuição dos grãos de anfibólio e piroxênio é muito semelhante, somente se diferenciando por um leve enriquecimento relativo dos anfibólios (Tab. 3).

COMPOSIÇÃO QUÍMICA DOS MINERAIS DETRÍTICOS E SUA APLICAÇÃO NA PROVENIÊNCIA Os estudos de química mineral em grãos detríticos têm um importante papel na determinação da origem dos grãos analisados, embora não possam indicar clara e diretamente o quanto os grãos foram reciclados (Morton, 1991). Com o presente estudo, pretende-se, portanto, definir a origem primária dos grãos pesados detríticos dos sedimentos do litoral norte do estado do Rio Grande do Sul.

Piroxênio A composição dos piroxênios magmáticos (Tab. 4) reflete a afinidade química do magmatismo que o produziu e, conseqüentemente, seu provável ambiente tectônico. Diopsídio, augita e hiperstênio são também importantes minerais de rochas metamórficas de alto grau. Os piroxênios encontrados nas amostras estudadas (Fig. 2) são diopsídio, augita baixo cálcio e hiperstênio. Os grãos de augita apresentam conteúdos de cálcio menores do que os encontrados nas augitas típicas da Formação Serra Geral descritas por Viero \& Roisenberg (1992). Os grãos de diopsídio são composicionalmente similares aos identificados em granulitos do Escudo Sul-rio-grandense e os grãos de hiperstênio mostram conteúdos de enstatita semelhantes aos referidos por Silva et al. (2002) no Complexo Várzea do Capivarita, na porção nordeste do Escudo Sul-rio-grandense.

Letterrier et al. (1982) avaliam a proveniência de piroxênios pela análise do conteúdo de $\mathrm{Ca}, \mathrm{Ti}, \mathrm{Cr}, \mathrm{Na}$ e Al, discriminando o ambiente tectônico das rochas basálticas alteradas que lhes deram origem. $\mathrm{O}$ esquema abrange três estágios: (a) piroxênios de fontes toleíticas e cálcio- alcalinas são distinguidos daqueles de fontes alcalinas pelos teores de Ti e $(\mathrm{Ca}+\mathrm{Na})$; (b) os conteúdos de $(\mathrm{Ti}+\mathrm{Cr})$ versus $\mathrm{Ca}$, diferenciam piroxênios não orogênicos dos orogênicos e, (c) a distinção de piroxênios orogênicos, de suítes cálcio-alcalinas e de toleíticas, é feita pelos seus conteúdos de $\mathrm{Al}$ e Ti. Os piroxênios deste estudo, no diagrama de Ti versus $(\mathrm{Ca}+\mathrm{Na})$, encontram-se no campo dos piroxênios de rochas cálcio alcalinas e toleíticas (Fig. 3).

Tabela 2 - Percentagem em peso de minerais leves e pesados nas frações areia muito fina, fina e média.

\begin{tabular}{l|c|c|c|c|c|c}
\hline & \multicolumn{3}{|c|}{ LEVES } & \multicolumn{3}{c}{ PESADOS } \\
\cline { 2 - 7 } & $\begin{array}{c}\text { Areia } \\
\text { Muito Fina }\end{array}$ & $\begin{array}{c}\text { Areia } \\
\text { Fina }\end{array}$ & $\begin{array}{c}\text { Areia } \\
\text { Média }\end{array}$ & $\begin{array}{c}\text { Areia } \\
\text { Muito Fina }\end{array}$ & $\begin{array}{c}\text { Areia } \\
\text { Fina }\end{array}$ & $\begin{array}{c}\text { Areia } \\
\text { Média }\end{array}$ \\
\cline { 2 - 7 } & $\Phi=4-3$ & $\Phi=3-2$ & $\Phi=2-1$ & $\Phi=4-3$ & $\Phi=3-2$ & $\Phi=2-1$ \\
\hline Amostra 11 & 33,68 & 65,53 & 0,45 & 0,33 & 0,01 & 0,00 \\
Amostra 10 & 29,84 & 68,02 & 1,77 & 0,36 & 0,01 & 0,00 \\
Amostra 9 & 31,92 & 63,67 & 3,81 & 0,59 & 0,01 & 0,00 \\
Amostra 8 & 18,94 & 77,52 & 3,43 & 0,11 & 0,00 & 0,00 \\
Amostra 7 & 14,05 & 78,62 & 6,86 & 0,46 & 0,01 & 0,00 \\
\hline
\end{tabular}


Tabela 3 - Variação modal dos minerais detríticos pesados nas frações areia muito fina (\% em peso).

\begin{tabular}{l|ccccc}
\hline & \multicolumn{5}{|c}{ Amostras } \\
& 7 & 8 & 9 & 10 & 11 \\
\hline Zircão & 3 & 1 & $<1$ & 1 & 1 \\
Rutilo & 1 & 1 & $<1$ & 1 & 1 \\
Alumino-silicatos & 5 & 1 & 2 & 2 & 3 \\
Estaurolita & 2 & 1 & $<1$ & 1 & 1 \\
Granadas & 6 & 4 & 6 & 6 & 1 \\
Ilmenita+ magnetita & 21 & 21 & 33 & 26 & 21 \\
Apatita & $<1$ & $<1$ & $<1$ & $<1$ & $<1$ \\
Epidotos & 23 & 26 & 23 & 24 & 30 \\
Turmalinas & 15 & 18 & 14 & 16 & 14 \\
Anfibólios & 11 & 14 & 10 & 12 & 13 \\
Piroxênios & 7 & 10 & 8 & 9 & 11 \\
Titanita & 6 & 3 & 4 & 2 & 6 \\
\hline
\end{tabular}

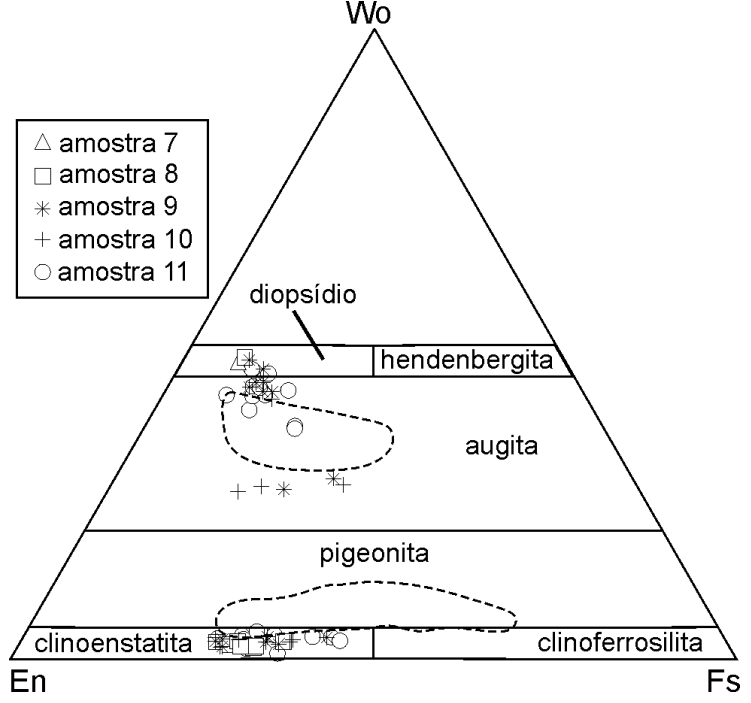

Figura 2 - Classificação dos piroxênios (Morimoto et al. 1988) da fração granulométrica de areia muito fina das amostras analisadas. Wo - Wolastonita, En - Enstatita, Fs - Ferrosilita, campo tracejado - Formação Serra Geral.

Tabela 4 - Composição química dos piroxênios (\% em peso). (nd - não detectado).

\begin{tabular}{|c|c|c|c|c|c|c|c|c|c|c|c|c|c|c|}
\hline Amostras & 7 & 8 & 8 & 8 & 8 & 8 & 8 & 8 & 8 & 8 & 9 & 9 & 9 & 9 \\
\hline $\mathrm{SiO}_{2}$ & 50,91 & 52,56 & 51,65 & 52,14 & 52,37 & 53,38 & 50,44 & 46,85 & 51,61 & 50,82 & 51,90 & 52,04 & 51,95 & 52,43 \\
\hline $\mathrm{Al}_{2} \mathrm{O}_{3}$ & 5,59 & 1,10 & 0,38 & 0,35 & 1,08 & 0,58 & 4,33 & 6,21 & 3,80 & 1,78 & 1,06 & 0,86 & 0,74 & 0,78 \\
\hline $\mathrm{Cr}_{2} \mathrm{O}_{3}$ & 0,59 & 1,54 & nd & 1,04 & nd & nd & 3,96 & 6,85 & 5,17 & nd & 1,29 & 1,27 & nd & nd \\
\hline $\mathrm{TiO}_{2}$ & 0,54 & 0,47 & 0,18 & 0,20 & 0,30 & 0,20 & 0,47 & 0,52 & 0,36 & 0,59 & 0,31 & 0,24 & 0,35 & 0,19 \\
\hline $\mathrm{MgO}$ & 15,14 & 25,18 & 21,73 & 22,00 & 26,23 & 26,34 & 16,78 & 12,21 & 18,10 & 15,25 & 25,96 & 22,95 & 22,08 & 23,53 \\
\hline $\mathrm{FeO}$ & 4,68 & 19,42 & 22,94 & 22,93 & 17,32 & 17,18 & 11,33 & 16,61 & 10,23 & 9,16 & 18,01 & 21,21 & 21,57 & 21,44 \\
\hline $\mathrm{MnO}$ & 0,15 & 0,49 & 1,34 & 1,16 & 0,48 & 1,54 & 0,50 & 0,48 & 0,17 & 0,44 & 0,46 & 0,79 & 1,07 & 0,79 \\
\hline $\mathrm{NiO}$ & nd & nd & nd & nd & nd & nd & nd & nd & nd & nd & nd & nd & nd & nd \\
\hline $\mathrm{CaO}$ & 21,89 & 1,56 & 1,58 & 1,52 & 1,75 & 1,15 & 12,60 & 11,69 & 12,22 & 20,42 & 1,62 & 1,78 & 1,20 & 1,52 \\
\hline $\mathrm{Na}_{2} \mathrm{O}$ & 0,32 & 0,04 & 0,03 & 0,07 & 0,01 & 0,02 & 0,34 & 0,52 & 0,49 & 0,37 & 0,01 & 0,05 & 0,05 & 0,04 \\
\hline $\mathrm{K}_{2} \mathrm{O}$ & 0,01 & nd & nd & nd & nd & 0,01 & 0,19 & 0,33 & 0,12 & nd & nd & nd & nd & 0,01 \\
\hline Total & 99,82 & 102,36 & 99,83 & 101,41 & 99,54 & 100,40 & 100,94 & 102,27 & 102,27 & 98,83 & 100,62 & 101,19 & 99,01 & 100,73 \\
\hline Amostras & 9 & 9 & 9 & 9 & 9 & 9 & 9 & 9 & 9 & 10 & 10 & 10 & 10 & 10 \\
\hline $\mathrm{SiO}_{2}$ & 52,36 & 52,83 & 47,79 & 51,33 & 47,47 & 48,95 & 51,27 & 49,31 & 50,60 & 53,06 & 54,31 & 54,76 & 53,83 & 53,56 \\
\hline $\mathrm{Al}_{2} \mathrm{O}_{3}$ & 1,58 & 1,25 & 6,94 & 2,29 & 6,58 & 4,43 & 2,36 & 4,46 & 2,75 & 2,72 & 0,32 & 0,51 & 1,21 & 0,47 \\
\hline $\mathrm{Cr}_{2} \mathrm{O}_{3}$ & nd & 4,83 & 1,48 & 1,81 & 4,92 & 0,21 & 0,07 & 0,03 & 0,56 & 0,31 & nd & nd & nd & nd \\
\hline $\mathrm{TiO}_{2}$ & 0,37 & 0,26 & 0,68 & 0,24 & 1,02 & 0,80 & 0,87 & 1,13 & 0,96 & 0,42 & 0,17 & 0,05 & 0,36 & 0,18 \\
\hline $\mathrm{MgO}$ & 26,70 & 26,04 & 12,47 & 17,32 & 15,20 & 15,41 & 15,63 & 14,75 & 15,50 & 15,20 & 23,37 & 23,26 & 23,88 & 21,72 \\
\hline $\mathrm{FeO}$ & 17,49 & 18,12 & 15,89 & 23,10 & 13,01 & 8,28 & 7,97 & 8,78 & 7,26 & 5,15 & 19,81 & 19,52 & 18,50 & 22,24 \\
\hline $\mathrm{MnO}$ & 0,52 & 0,67 & 0,41 & 0,66 & 0,42 & 0,18 & 0,25 & 0,24 & 0,19 & 0,09 & 1,28 & 1,10 & 0,54 & 0,74 \\
\hline $\mathrm{NiO}$ & nd & nd & nd & nd & nd & nd & nd & nd & nd & nd & nd & 0,01 & 0,05 & nd \\
\hline $\mathrm{CaO}$ & 1,55 & 1,10 & 12,14 & 1,56 & 11,72 & 20,91 & 22,02 & 20,30 & 21,52 & 23,27 & 1,12 & 0,98 & 1,37 & 1,34 \\
\hline $\mathrm{Na}_{2} \mathrm{O}$ & 0,02 & 0,02 & 0,78 & 0,40 & 0,71 & 0,35 & 0,31 & 0,51 & 0,33 & 0,34 & 0,01 & nd & nd & 0,00 \\
\hline $\mathrm{K}_{2} \mathrm{O}$ & 0,01 & nd & 0,29 & 0,01 & 0,15 & nd & 0,01 & nd & nd & nd & 0,01 & nd & nd & 0,01 \\
\hline Total & 100,60 & 105,12 & 98,87 & 98,72 & 101,20 & 99,52 & 100,76 & 99,51 & 99,67 & 100,56 & 100,40 & 100,19 & 99,74 & 100,26 \\
\hline
\end{tabular}


Tabela 4 - Continuação.

\begin{tabular}{|c|c|c|c|c|c|c|c|c|c|c|c|c|c|c|}
\hline Amostras & 10 & 10 & 10 & 11 & 11 & 11 & 11 & 11 & 11 & 11 & 11 & 11 & 11 & 11 \\
\hline $\mathrm{SiO}_{2}$ & 54,89 & 54,30 & 54,49 & 54,51 & 53,89 & 51,98 & 53,62 & 52,60 & 53,39 & 52,09 & 52,52 & 53,95 & 52,54 & 51,82 \\
\hline $\mathrm{Al}_{2} \mathrm{O}_{3}$ & 0,35 & 1,11 & 0,93 & 1,31 & 1,60 & 0,98 & 1,03 & 0,69 & 0,93 & 1,51 & 2,57 & 0,84 & 2,34 & 0,68 \\
\hline $\mathrm{Cr}_{2} \mathrm{O}_{3}$ & 0,02 & 0,09 & 0,03 & 0,06 & 0,08 & 0,01 & 0,06 & 0,02 & nd & 0,04 & nd & 0,01 & 0,01 & 0,04 \\
\hline $\mathrm{TiO}_{2}$ & 0,20 & 0,25 & 0,32 & 0,39 & 0,36 & 0,43 & 0,48 & 0,26 & 0,13 & 0,67 & 0,09 & 0,23 & 0,53 & 0,20 \\
\hline $\mathrm{MgO}$ & 24,01 & 24,49 & 25,70 & 24,05 & 25,30 & 18,66 & 23,66 & 19,95 & 22,67 & 14,85 & 22,02 & 23,49 & 13,92 & 18,13 \\
\hline $\mathrm{FeO}$ & 18,13 & 17,80 & 16,81 & 18,94 & 16,99 & 24,97 & 18,75 & 23,51 & 19,90 & 12,72 & 22,40 & 19,95 & 9,84 & 25,75 \\
\hline $\mathrm{MnO}$ & 1,52 & 0,85 & 0,98 & 0,63 & 0,40 & 1,11 & 0,76 & 1,46 & 0,93 & 0,24 & 0,35 & 0,69 & 0,59 & 0,74 \\
\hline $\mathrm{NiO}$ & 0,02 & nd & 0,01 & nd & nd & nd & 0,04 & nd & 0,02 & 0,01 & nd & nd & 0,04 & 0,01 \\
\hline $\mathrm{CaO}$ & 1,03 & 1,18 & 1,34 & 1,73 & 1,54 & 1,45 & 1,43 & 1,61 & 1,23 & 17,84 & 0,51 & 1,20 & 20,46 & 1,24 \\
\hline $\mathrm{Na}_{2} \mathrm{O}$ & nd & nd & 0,85 & 0,03 & 0,01 & 0,03 & nd & 0,01 & 0,01 & 0,15 & nd & 0,03 & 0,46 & nd \\
\hline $\mathrm{K}_{2} \mathrm{O}$ & nd & nd & 0,06 & 0,01 & 0,01 & 0,01 & nd & 0,02 & nd & nd & 0,01 & nd & nd & nd \\
\hline Total & 100,17 & 100,07 & 101,52 & 101,66 & 100,18 & 99,63 & 99,83 & 100,13 & 99,21 & 100,12 & 100,47 & 100,39 & 100,73 & 98,61 \\
\hline
\end{tabular}

\begin{tabular}{|c|c|c|c|c|c|c|c|c|c|c|c|c|c|c|c|}
\hline Amostras & 11 & 11 & 11 & 11 & 11 & 11 & 11 & 11 & 11 & 11 & 11 & 11 & 11 & 11 & 11 \\
\hline $\mathrm{SiO}_{2}$ & 54,24 & 51,26 & 54,58 & 53,40 & 51,77 & 52,27 & 51,54 & 50,87 & 52,29 & 48,18 & 48,20 & 49,98 & 52,79 & 52,35 & 50,78 \\
\hline $\mathrm{Al}_{2} \mathrm{O}_{3}$ & 0,28 & 3,41 & 0,36 & 1,22 & 2,96 & 2,24 & 2,28 & 2,66 & 1,04 & 5,68 & 5,40 & 3,67 & 1,91 & 1,94 & 4,21 \\
\hline $\mathrm{Cr}_{2} \mathrm{O}_{3}$ & nd & 0,04 & nd & 0,01 & 0,30 & 0,70 & 0,04 & nd & nd & 0,45 & 0,26 & 0,37 & 0,12 & nd & 0,19 \\
\hline $\mathrm{TiO}_{2}$ & nd & 0,27 & nd & 0,29 & 0,20 & 0,66 & 0,61 & 1,03 & 0,32 & 1,12 & 0,73 & 0,89 & 0,25 & 0,56 & 0,58 \\
\hline $\mathrm{MgO}$ & 14,95 & 13,79 & 24,05 & 22,06 & 14,82 & 16,11 & 14,78 & 14,96 & 22,78 & 14,13 & 13,94 & 15,00 & 17,09 & 15,91 & 15,28 \\
\hline $\mathrm{FeO}$ & 7,66 & 11,69 & 19,40 & 21,18 & 5,96 & 7,74 & 7,40 & 8,28 & 19,57 & 5,30 & 6,81 & 6,96 & 5,26 & 7,67 & 6,57 \\
\hline $\mathrm{MnO}$ & 0,41 & 0,26 & 0,97 & 0,69 & 0,17 & 0,18 & 0,46 & 0,34 & 0,47 & 0,13 & 0,09 & 0,23 & 0,13 & 0,26 & 0,14 \\
\hline $\mathrm{NiO}$ & 0,01 & 0,06 & nd & 0,02 & 0,04 & nd & nd & 0,02 & 0,02 & nd & nd & nd & nd & nd & 0,01 \\
\hline $\mathrm{CaO}$ & 22,28 & 16,47 & 0,94 & 1,73 & 21,43 & 18,71 & 20,73 & 19,82 & 2,11 & 21,65 & 21,40 & 19,90 & 20,18 & 19,99 & 20,19 \\
\hline $\mathrm{Na}_{2} \mathrm{O}$ & 0,31 & 0,55 & 0,01 & 0,03 & 0,24 & 0,21 & 0,26 & 0,32 & 0,03 & 0,25 & 0,24 & 0,33 & 0,14 & 0,27 & 0,28 \\
\hline $\mathrm{K}_{2} \mathrm{O}$ & 0,02 & 0,15 & nd & nd & nd & 0,01 & nd & nd & 0,01 & nd & nd & nd & 0,01 & nd & nd \\
\hline Total & 100,16 & 97,95 & 100,31 & 100,63 & 97,89 & 98,83 & 98,10 & 98,30 & 98,64 & 96,89 & 97,07 & 97,33 & 97,88 & 98,95 & 98,23 \\
\hline
\end{tabular}

Os conteúdos de $\mathrm{SiO}_{2}$ e $\mathrm{Al}_{2} \mathrm{O}_{3}$ de piroxênios são utilizados por Le Bas (1962) para diferenciar clinopiroxênios gerados de rochas alcalinas, subalcalinas ou peralcalinas. Os grãos de piroxênios das amostras estudadas situamse dominantemente no campo das rochas subalcalinas, e apenas alguns grãos das amostras 9 e 11 posicionam-se no campo correspondente aos de rochas alcalinas (Fig. 4).

A abundância de $\mathrm{SiO}_{2}, \mathrm{Al}_{2} \mathrm{O}_{3}, \mathrm{FeO}_{\mathrm{T}}, \mathrm{MnO}, \mathrm{MgO}$, $\mathrm{CaO}, \mathrm{Na}_{2} \mathrm{O}$ em clinopiroxênios é utilizada por Nisbet \& Pearce (1977) para identificar o ambiente de rochas básicas que lhes deram origem. De acordo com esses critérios, os clinopiroxênios estudados são provenientes de rochas básicas de fundo oceânico ou de arco vulcânico (Fig. 5).

A consideração dos critérios de forma integrada sugere que os grãos de piroxênios dos sedimentos estudados provêm de rochas metamórficas da fácies granulito e de rochas básicas toleíticas relacionadas com ambientes pós-colisionais, como as referidas por Florisbal et al. (2005) no sul de Santa Catarina e que ocorrem associadas aos granitóides mais precoces do Batólito Pelotas (Bitencourt \& Nardi 2000).

Anfibólio A utilização da química do anfibólio é altamente relevante em estudos de proveniência, uma vez que o vasto espectro composicional dos anfibólios reflete uma larga variedade de fontes (Morton 1991).

As rochas graníticas ígneas de associações magmáticas distintas, freqüentemente retratando ambientes tectônicos diversos, podem mostrar anfibólios de composição característica. Assim, granitóides cálcioalcalinos associados a ambientes de arcos magmáticos, comumente possuem anfibólios cálcicos com razões $\mathrm{FeO}_{\mathrm{T}} /\left(\mathrm{FeO}_{\mathrm{T}}+\mathrm{MgO}\right)$ inferior a 0,70 , enquanto granitóides de associações pós-colisionais e principalmente anorogênicos tendem a ser os mais ricos em álcalis e apresentar razões $\mathrm{FeO}_{\mathrm{T}} /\left(\mathrm{FeO}_{\mathrm{T}}+\mathrm{MgO}\right)$ mais elevadas (Nardi 1991). Associações pós-colisionais e anorogênicas podem conter rochas intermediárias e ácidas com anfibólios sódicos.

A maior parte dos grãos analisados (Tab. 5) apresentam razões $\mathrm{FeO}_{\mathrm{T}} /\left(\mathrm{FeO}_{\mathrm{T}}+\mathrm{MgO}\right)<0,7$ que indicam anfibólios metamórficos, ou de granitóides subalcalinos, também referidos como do tipo I, ou ainda de rochas intermediárias. Nas amostras $8,9,10$ e $11 \mathrm{e}$, em poucos grãos, observam-se razões $\mathrm{FeO}_{\mathrm{T}} /\left(\mathrm{FeO}_{\mathrm{T}}+\mathrm{MgO}\right)$ superiores a 0,7 , comuns em anfibólios de granitóides do tipo A.

Os anfibólios identificados nas amostras 8, 9, 10, e 11 (Tab. 5) têm composições de Mg-hornblenda, acti- 
nolita, actinolita hornblenda, edenita, edenita hornblenda, Fe-hornblenda, Mg-cumintonita antofilita, Mg-hastingsita hornblenda, pargasita - hornblenda, tchermakita e tremolita. A maior parte dos grãos mostra composições de anfibólios metamórficos, freqüentemente derivados de rochas máficas e ultramáficas e de seqüências margosas. Anfibólios de rochas graníticas, tanto do tipo I como A, são encontrados em pequenas quantidades.

A amostra 7 apresenta somente actinolita e actinolita hornblenda, que podem provir de fontes metamórficas de baixo grau (xisto verde) ou de rochas hidrotermalizadas.

Epidoto O grupo do epidoto (zoisita, clinozoisita, epidoto, alanita e piemontita) apresenta um grande intervalo na composição. A estabilidade do epidoto no ciclo sedimentar é relativamente reduzida, embora maior que a dos anfibólios (Morton 1984). De acordo com diversos autores (Zen \& Hammarstrom 1984; Campos et al. 2005), epidotos podem possuir conteúdos de componentes pistacita $\left(\mathrm{PS}=\mathrm{Fe}^{+3} /\left(\mathrm{Fe}^{+3}+\mathrm{Al}\right)\right)$ variáveis, conforme sua origem. Epidotos magmáticos de granitos metaluminosos cristalizados em profundidades superiores a $15 \mathrm{~km}$, apresentam PS entre 0,2 a 0,3 e em epidotos secundários (rochas metamórficas ou hidrotermais) a componente PS é inferior a 0,2 ou

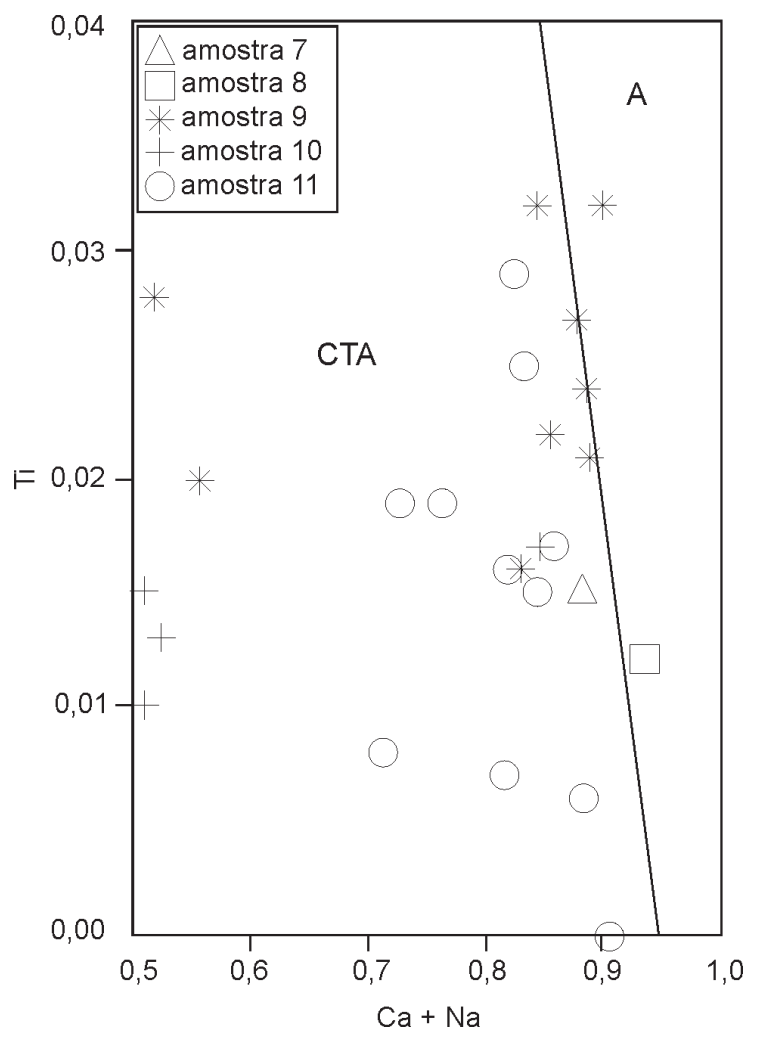

Figura 3 - Classificação dos clinopiroxênios (Leterrier et al. 1982) da fração granulométrica de areia muito fina das amostras analisadas. CTA - cálcio-alcalinos e toleíticos, $A$-alcalinos.

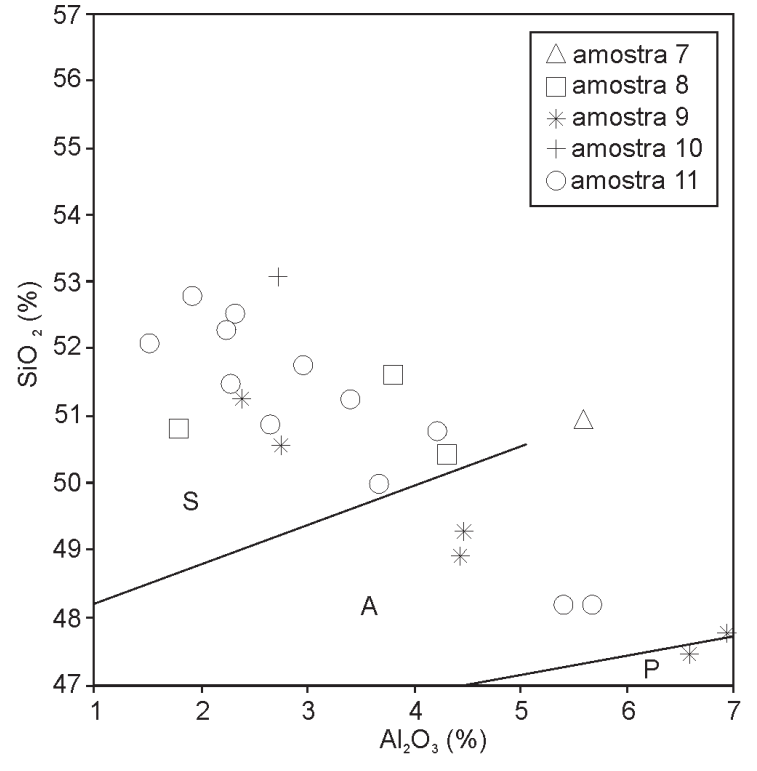

Figura 4 - Classificação dos clinopiroxênios (Le Bas 1962) da fração granulométrica de areia muito fina das amostras analisadas. $S-$ Subalcalino, A-Alcalino, $P$-Peralcalino.

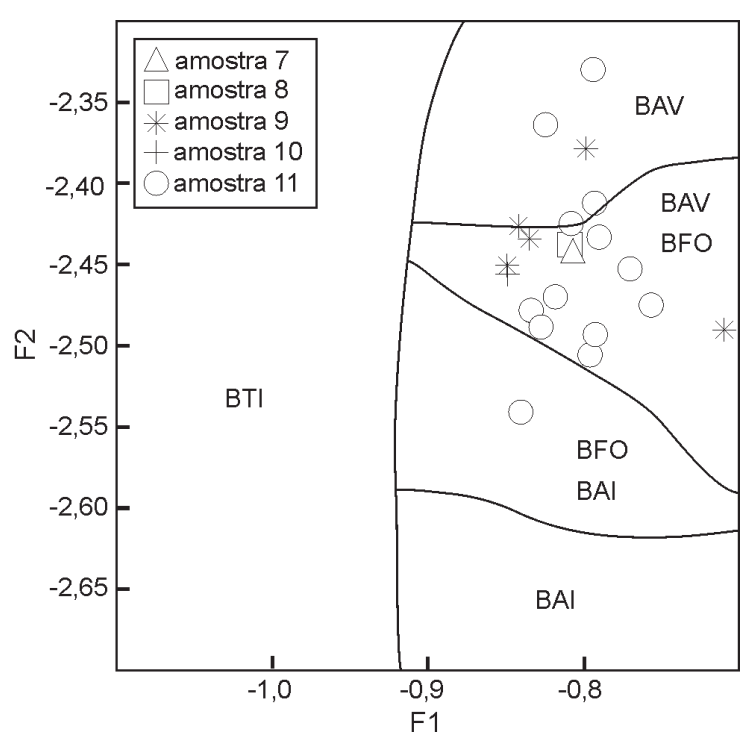

Figura 5 - Campo das composições dos clinopiroxênios da fração granulométrica de areia muito fina das amostras analisadas. (modificado de Nisbet \& Pearce 1977). BFO-Basalto de Fundo Oceânico, BAV - Basalto de Arco Vulcânico, BTI - Basalto Toleitico Intraplaca, BAI - Basalto Alcalino Intraplaca. F1 = - $(0.012$ $\left.x \mathrm{SiO}_{2}\right)-\left(0.0807 \times \mathrm{TiO}_{2}\right)+\left(0.0026 \times \mathrm{Al}_{2} \mathrm{O}_{3}\right)-$ $(0.0012 x \mathrm{FeO} *)-(0.0026 x \mathrm{MnO})+(0.0087 x$ $\mathrm{MgO})-(0.0128 \times \mathrm{CaO})-\left(0.0419 \times \mathrm{Na}_{2} \mathrm{O}\right) ; \mathrm{F} 2$ $=-\left(0.0469 \times \mathrm{SiO}_{2}\right)-\left(0.0818 \times \mathrm{TiO}_{2}\right)-(0.0212$ $\left.x \mathrm{Al}_{2} \mathrm{O}_{3}\right)-(0.0041 \times \mathrm{FeO} *)-(0.1435 \times \mathrm{MnO})-$ $(0.0029 \times \mathrm{MgO})+(0.0085 \times \mathrm{CaO})+(0.016 \times$ $\left.\mathrm{Na}_{2} \mathrm{O}\right)$. 
Tabela 5 - Composição química dos anfibólios (\% em peso). (nd - não detectado).

\begin{tabular}{l|cccccccccccccccc}
\hline Amostras & 7 & 7 & 7 & 7 & 7 & 7 & 8 & 8 & 8 & 8 & 8 & 8 & 8 & 8 & 8 & 8 \\
\hline $\mathrm{SiO}_{2}$ & 54,63 & 53,89 & 55,41 & 53,05 & 56,95 & 57,1 & 53,92 & 43,64 & 45,52 & 46,37 & 46,22 & 56,77 & 55,36 & 55,88 & 46,87 & 48,29 \\
$\mathrm{TiO}_{2}$ & 0,12 & 0,28 & 0,30 & 0,12 & 0,11 & 0,04 & 0,10 & 0,73 & 1,19 & 1,38 & 1,04 & nd & 0,06 & 0,03 & 0,48 & 0,41 \\
$\mathrm{Al}_{2} \mathrm{O}_{3}$ & 3,21 & 3,67 & 2,52 & 4,15 & 1,63 & 1,61 & 1,26 & 8,85 & 8,47 & 6,57 & 6,87 & 0,24 & 0,86 & 0,18 & 6,83 & 7,73 \\
$\mathrm{FeO}$ & 6,80 & 7,76 & 7,94 & 8,52 & 7,03 & 5,70 & 17,60 & 17,79 & 13,87 & 14,70 & 14,70 & 11,5 & 14,56 & 14,84 & 13,19 & 11,73 \\
$\mathrm{Cr}_{2} \mathrm{O}_{3}$ & 0,01 & 0,19 & 0,12 & 0,39 & 0,29 & 0,22 & 0,46 & nd & nd & 1,26 & 0,04 & 0,01 & 0,12 & 0,08 & 0,05 & 0,11 \\
$\mathrm{MnO}$ & 0,17 & 0,19 & 0,30 & 0,14 & 0,27 & 0,19 & 1,06 & 0,30 & 0,48 & 0,58 & 0,52 & 0,46 & 0,25 & 0,40 & 0,39 & 0,26 \\
$\mathrm{MgO}$ & 18,57 & 17,82 & 18,91 & 16,93 & 19,41 & 19,75 & 21,92 & 11,37 & 14,08 & 13,77 & 13,10 & 26,53 & 23,85 & 23,99 & 14,51 & 14,18 \\
$\mathrm{CaO}$ & 12,71 & 12,21 & 11,53 & 12,35 & 11,04 & 11,93 & 1,34 & 12,23 & 11,55 & 11,42 & 11,83 & 0,59 & 1,10 & 0,76 & 11,76 & 12,55 \\
$\mathrm{Na}$ & 0,30 & 0,56 & 0,48 & 0,58 & 0,49 & 0,15 & 0,21 & 1,21 & 1,48 & 1,29 & 1,09 & 0,01 & 0,11 & 0,03 & 0,82 & 0,89 \\
$\mathrm{~K}_{2} \mathrm{O}$ & 0,27 & 0,36 & 0,04 & 0,29 & 0,29 & 0,03 & nd & 0,88 & 0,34 & 0,55 & 0,54 & nd & 0,01 & nd & 0,48 & 0,57 \\
$\mathrm{~F}$ & 0,12 & 0,09 & 0,07 & nd & 0,04 & 0,08 & nd & nd & nd & nd & nd & nd & nd & nd & nd & nd \\
$\mathrm{Cl}$ & 0,03 & 0,04 & nd & 0,02 & nd & nd & nd & nd & nd & nd & nd & nd & nd & nd & nd & nd \\
\hline Total & 96,94 & 97,06 & 97,62 & 96,54 & 97,55 & 96,80 & 97,87 & 97,00 & 96,98 & 97,89 & 95,95 & 96,11 & 96,28 & 96,19 & 95,38 & 96,72 \\
\hline
\end{tabular}

\begin{tabular}{|c|c|c|c|c|c|c|c|c|c|c|c|c|c|c|c|c|}
\hline Amo & 8 & 8 & 8 & 8 & 8 & 8 & 8 & 8 & 8 & 8 & 8 & 8 & 8 & 9 & 9 & 9 \\
\hline $\mathrm{SiO}_{2}$ & 841 & 3,38 & 71 & $20 ?$ & 17 & 04 & 2,44 & 5,64 & 9,73 & 52,27 & 1489 & 8,31 & 51,85 & 3,79 & 8,08 & 45,81 \\
\hline $\mathrm{TiO}_{2}$ & 0,68 & 0,01 & 0,37 & 056 & 2,03 & 0.83 & 337 & 160 & 023 & 013 & 0.90 & 015 & 028 & 014 & 0,72 & 0,89 \\
\hline $\mathrm{Al}_{2} \mathrm{O}_{3}$ & 5,53 & 1,73 & 9,81 & 5,32 & 12,77 & 6,67 & 10,15 & 7,71 & 5,42 & 3,09 & 6,62 & 8,41 & 2,48 & 1,82 & 5,83 & 7,57 \\
\hline $\mathrm{FeO}$ & 12,96 & 10,88 & 14,52 & 11,99 & 9,91 & 12,12 & 11,26 & 15,15 & 11,82 & 8,64 & 16,93 & 10,33 & 10,03 & 16,69 & 13,85 & 16,07 \\
\hline $\mathrm{Cr}_{2} \mathrm{O}_{3}$ & 0,38 & 0,22 & 0,07 & 02 & 014 & 0,01 & 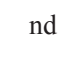 & d & 0 & 0,17 & d & 0 & 000 & nd & d & 0,14 \\
\hline $\mathrm{MnO}$ & 0,24 & 0,24 & 0,22 & 0,31 & 0,14 & 0,38 & 0,49 & 0,35 & 0,22 & 0,15 & 0,73 & 0,24 & 0,13 & 1,04 & 0,48 & 0,55 \\
\hline $\mathrm{MgO}$ & 14,13 & 16,61 & 12,51 & 14,86 & 14,96 & 16,00 & 14,47 & 13,33 & 15,04 & 17,91 & 11,28 & 15,07 & 17,73 & 21,79 & 14,47 & 12,45 \\
\hline $\mathrm{CaO}$ & 12,45 & 13,24 & 10,83 & 12,41 & 11,94 & 10,46 & 11,24 & 10,74 & 12,64 & 12,97 & 11,62 & 11,84 & 12,05 & 1,57 & 12,47 & 12,15 \\
\hline $\mathrm{Na}_{2} \mathrm{O}$ & 0,97 & 0,25 & 1,94 & 0,73 & 2,32 & 1,23 & 2,57 & 1,54 & 0,55 & 0,50 & 0,99 & 1,26 & 0,63 & 0,28 & 0,86 & 0,99 \\
\hline $\mathrm{K}_{2} \mathrm{O}$ & 0,54 & 0,13 & 0,15 & 0,46 & 0,27 & 0,11 & 0,77 & 0,43 & 0,06 & 0,08 & 0,61 & 0,15 & 0,18 & 0,02 & 0,50 & 0,57 \\
\hline 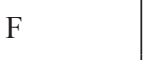 & nd & nd & nd & nd & nd & nd & nd & nd & nd & nd & nd & 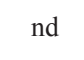 & nd & nd & nd & nd \\
\hline $\mathrm{Cl}$ & nd & nd & nd & nd & 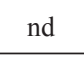 & nd & nd & nd & nd & nd & nd & nd & nd & nd & nd & nd \\
\hline tal & 6,29 & 6,69 & 96,13 & 6,20 & 95,95 & 5,85 & 96,76 & 96,49 & 95,76 & 95,91 & 94,57 & 96,16 & 95,45 & 97,14 & 97,26 & 97,19 \\
\hline
\end{tabular}

\begin{tabular}{l|cccccccccccccccc}
\hline Amostras & 9 & 9 & 9 & 9 & 9 & 9 & 9 & 9 & 9 & 9 & 9 & 9 & 9 & 9 & 9 & 9 \\
\hline $\mathrm{SiO}_{2}$ & 42,94 & 46,34 & 47,4 & 41,99 & 47,48 & 50,48 & 52,38 & 46,04 & 53,81 & 46,91 & 42,56 & 50,00 & 48,35 & 46,55 & 50,63 & 54,48 \\
$\mathrm{TiO}_{2}$ & 1,27 & 0,92 & 0,10 & 3,36 & 1,14 & 0,29 & 0,22 & 0,28 & 0,30 & 0,87 & 3,15 & 0,59 & 1,13 & 0,37 & 0,08 & 0,23 \\
$\mathrm{Al}_{2} \mathrm{O}_{3}$ & 11,19 & 7,23 & 16,29 & 11,01 & 7,75 & 5,48 & 4,14 & 11,16 & 2,33 & 7,89 & 9,76 & 4,76 & 6,62 & 8,94 & 4,73 & 1,71 \\
$\mathrm{FeO}$ & 14,94 & 16,41 & 13,18 & 14,27 & 12,99 & 10,8 & 9,42 & 10,30 & 9,91 & 13,10 & 15,4 & 12,91 & 10,99 & 11,72 & 15,16 & 15,72 \\
$\mathrm{Cr}_{2} \mathrm{O}_{3}$ & nd & nd & nd & nd & nd & 0,19 & 0,30 & 0,17 & 0,63 & 0,07 & nd & 0,02 & 0,03 & 0,13 & 0,13 & 0,03 \\
$\mathrm{MnO}$ & 0,42 & 0,30 & 0,22 & 0,3 & 0,65 & 0,29 & 0,24 & 0,33 & 0,20 & 0,73 & 0,39 & 0,51 & 0,40 & 0,27 & 0,27 & 0,95 \\
$\mathrm{MgO}$ & 12,23 & 11,90 & 0,10 & 12,31 & 15,21 & 16,00 & 17,84 & 14,65 & 18,57 & 15,12 & 11,92 & 15 & 16,70 & 14,89 & 13,23 & 21,72 \\
$\mathrm{CaO}$ & 11,12 & 12,50 & 19,3 & 11,26 & 10,64 & 12,55 & 12,31 & 11,96 & 11,79 & 10,42 & 11,07 & 12,41 & 11,22 & 11,79 & 12,91 & 2,02 \\
$\mathrm{Na} \mathrm{O}_{2}$ & 1,39 & 0,79 & 0,03 & 2,49 & 1,45 & 1,02 & 0,64 & 1,54 & 0,42 & 1,22 & 1,26 & 0,74 & 1,31 & 1,28 & 0,58 & 0,30 \\
$\mathrm{~K}_{2} \mathrm{O}$ & 0,61 & 0,73 & 0,02 & 0,68 & 0,26 & 0,39 & 0,13 & 0,36 & 0,12 & 0,25 & 0,85 & 0,39 & 0,14 & 0,81 & 0,20 & nd \\
$\mathrm{F}$ & nd & nd & nd & nd & nd & nd & nd & nd & nd & nd & nd & nd & nd & nd & nd & nd \\
$\mathrm{Cl}$ & nd & nd & nd & nd & nd & nd & nd & nd & nd & nd & nd & nd & nd & nd & nd & nd \\
\hline Total & 96,11 & 97,12 & 96,64 & 97,67 & 97,57 & 97,49 & 97,62 & 96,79 & 98,45 & 96,58 & 96,36 & 97,33 & 96,89 & 96,75 & 97,92 & 97,16 \\
\hline
\end{tabular}


Tabela 5 - Continuação.

\begin{tabular}{l|cccccccccccccccc}
\hline $\mathrm{Amostras}$ & 9 & 9 & 9 & 9 & 9 & 9 & 9 & 9 & 9 & 9 & 9 & 9 & 9 & 10 & 10 & 10 \\
\hline $\mathrm{SiO}_{2}$ & 47,78 & 50,95 & 51,45 & 50,47 & 49,63 & 47,97 & 53,32 & 45,21 & 52,08 & 53,97 & 49,32 & 41,55 & 53,83 & 44,43 & 47,55 & 48,41 \\
$\mathrm{TiO}_{2}$ & 1,18 & 0,33 & 0,33 & 0,22 & 0,50 & 0,74 & 0,17 & 0,08 & 0,09 & 0,10 & 0,49 & 1,69 & 0,20 & 1,22 & 1,63 & 1,15 \\
$\mathrm{Al}_{2} \mathrm{O}_{3}$ & 5,30 & 5,05 & 4,54 & 5,07 & 5,59 & 5,90 & 2,97 & 19,4 & 4,44 & 2,75 & 8,05 & 13,89 & 2,71 & 8,70 & 6,54 & 5,84 \\
$\mathrm{FeO}$ & 3,82 & 10,17 & 9,82 & 9,80 & 10,32 & 13,94 & 17,12 & 10,68 & 7,71 & 7,59 & 7,57 & 8,98 & 9,98 & 18,71 & 14,11 & 15,68 \\
$\mathrm{Cr}_{2} \mathrm{O}_{3}$ & nd & 0,11 & 0,07 & 0,15 & 0,33 & 0,01 & nd & nd & 0,15 & 0,20 & 0,47 & 0,04 & 0,20 & 0,03 & 0,05 & nd \\
$\mathrm{MnO}$ & 0,44 & 0,25 & 0,35 & 0,26 & 0,28 & 0,79 & 0,5 & 0,43 & 0,23 & 0,35 & 0,27 & 0,10 & 0,15 & 0,38 & 0,41 & 0,86 \\
$\mathrm{MgO}$ & 13,88 & 16,80 & 17,32 & 17,99 & 16,32 & 14,01 & 20,22 & 0,01 & 18,9 & 19,58 & 17,62 & 15,70 & 17,44 & 9,80 & 12,98 & 12,41 \\
$\mathrm{CaO}$ & 11,78 & 12,50 & 12,50 & 11,96 & 12,55 & 11,95 & 2,98 & 20,35 & 12,41 & 12,21 & 11,56 & 12,01 & 12,74 & 11,55 & 12,02 & 11,40 \\
$\mathrm{Na}$ & 1,15 & 0,73 & 0,98 & 0,82 & 1,02 & 0,93 & 0,38 & 0,03 & 0,56 & 0,35 & 1,39 & 2,45 & 0,37 & 1,00 & 0,60 & 0,91 \\
$\mathrm{~K}_{2} \mathrm{O}$ & 0,54 & 0,26 & 0,35 & 0,26 & 0,52 & 0,45 & 0,05 & nd & 0,11 & 0,04 & 1,39 & 0,28 & 0,07 & 1,04 & 0,62 & 0,54 \\
$\mathrm{~F}$ & nd & nd & nd & nd & nd & nd & nd & nd & nd & nd & nd & nd & nd & nd & 0,06 & 0,02 \\
$\mathrm{Cl}$ & nd & nd & nd & nd & nd & nd & nd & nd & nd & nd & nd & nd & nd & nd & 0,05 & 0,05 \\
\hline Total & 85,87 & 97,15 & 97,71 & 97,00 & 97,06 & 96,69 & 97,71 & 96,19 & 96,68 & 97,14 & 98,13 & 96,69 & 97,69 & 96,86 & 96,62 & 97,27 \\
\hline
\end{tabular}

\begin{tabular}{|c|c|c|c|c|c|c|c|c|c|c|c|c|c|c|c|c|c|}
\hline $\mathrm{Am}$ & 10 & 10 & 10 & 10 & 0 & 10 & 10 & 10 & 10 & 10 & 10 & 11 & 11 & 11 & 11 & 11 & 11 \\
\hline $\mathrm{SiO}_{2}$ & 2,13 & 77 & 513 &, 83 & 2,49 & 2,4 & 50,41 & 53,04 & 2,26 & 4,51 & 5,08 & 9,9 & 45,30 & 55,18 & 4,01 & 3,82 & 46,04 \\
\hline $\mathrm{TiO}_{2}$ & 0,38 & 0,41 & 0,45 & 0,85 & 0,35 & 0,36 & 0,4 & 0,18 & 0,36 & 3,12 & 2,61 & 0,97 & 0,80 & 1,31 & 0,13 & 0,31 & 0,80 \\
\hline $\mathrm{Al}_{2} \mathrm{O}_{3}$ & 4,68 & 5,68 & 5,78 & 12,37 & 5,11 & 4,17 & 6,42 & 5,91 & 6,00 & 8,97 & 8,43 & 6,17 & 9,12 & 2,17 & 1,89 & 2,38 & 9,67 \\
\hline $\mathrm{FeO}$ & 12,31 & 11,79 & 10,46 & 14,66 & 7,39 & 8,1 & 8,76 & 15,52 & 10,29 & 12,72 & 10,75 & 12,3 & 16,65 & 12,02 & 17,52 & 16,86 & 14,53 \\
\hline $\mathrm{Cr}_{2} \mathrm{O}_{3}$ & 0,11 & 0,15 & 0,03 & 0,01 & 0,30 & 0,34 & 0,53 & 0,28 & 0,24 & nd & nd & nd & nd & 0,04 & nd & nd & 0,03 \\
\hline $\mathrm{MnO}$ & 0,24 & 0,31 & 0,23 & 0,25 & 0,17 & 0,15 & 0,18 & 0,49 & 0,17 & 0,22 & 0,30 & 0,28 & 0,59 & 0,31 & 1,33 & 0,80 & 0,48 \\
\hline $\mathrm{MgO}$ & 15,06 & 15,90 & 16,54 & 10,18 & 18,60 & 18,26 & 16,76 & 20,98 & 28,17 & 13,68 & 14,97 & 14,87 & 10,94 & 13,00 & 20,28 & 19,98 & 12,33 \\
\hline $\mathrm{CaO}$ & 12,26 & 11,26 & 11,42 & 11,27 & 11,78 & 11,92 & 11,28 & 0,54 & 1,45 & 10,88 & 11,07 & 12,02 & 11,56 & 11,26 & 1,10 & 2,14 & 10,96 \\
\hline $\mathrm{Na}_{2} \mathrm{O}$ & 0,30 & 0,53 & 0,58 & 1,36 & 0,51 & 0,61 & 0,85 & 0,71 & nd & 1,75 & 1,99 & 0,65 & 0,82 & 1,47 & 0,17 & 0,32 & 0,99 \\
\hline $\mathrm{K}_{2} \mathrm{O}$ & 0,33 & 0,28 & 0,17 & 0,56 & 0,14 & 0,22 & 0,06 & 0,01 & nd & 0,59 & 0,62 & 0,30 & 1,00 & 0,24 & d & 0,02 & 0,54 \\
\hline$\Gamma$ & 0,02 & 0,10 & nd & 0,01 & 0,07 & 0,08 & nd & nd & nd & 0,06 & 0,23 & 0,03 & 0,04 & 0,04 & 0,06 & 4 & 0,04 \\
\hline $\mathrm{Cl}$ & 0,01 & 0,04 & 0,02 & 0,02 & 0,01 & nd & nd & nd & nd & 0,04 & 0,07 & nd & nd & 0,03 & 0,02 & 0,01 & 0,03 \\
\hline Total & 97,83 & 97,22 & 96,98 & 96,37 & 96,92 & 96,61 & 95,65 & 97,66 & 98,94 & 96,54 & 96,12 & 97,49 & 96,82 & 97,07 & 96,51 & 96,68 & 96,44 \\
\hline Amost & 11 & 11 & $\pi$ & & & 1 & 11 & 1 & \pm & 11 & & & 11 & & & 1 & 11 \\
\hline $\mathrm{SiO}_{2}$ & 5,02 & 44,34 & 46,76 & 46,78 & 48,74 & 45,25 & 44,83 & 47,64 & 42,61 & 46,88 & 44,35 & 46,89 & 50,05 & 48,22 & 43,84 & 54,39 & 49,75 \\
\hline $\mathrm{TiO}_{2}$ & 0,01 & 1,64 & 1 , & 1,76 & 0 & 1,06 & 1,21 & 75 & 1,55 & 0,70 & 1,46 & 0,37 & 0,58 & 1,44 & 1,63 & 0,01 & 0,45 \\
\hline $\mathrm{Al}_{2} \mathrm{O}_{3}$ & 0,78 & 916 & 8,34 & 7,72 & 5,46 & 10,07 & 8,58 & 6,39 & 9,73 & 8,39 & 9,61 & 9,6 & 5,22 & 7,39 & 11,67 & 3,81 & 6,53 \\
\hline $\mathrm{FeO}$ & 20,87 & 19,03 & 14,96 & 14,55 & 17,99 & 15,58 & 16,65 & 17,28 & 23,46 & 17,30 & 19,82 & 15,58 & 16,66 & 12,46 & 7,91 & 5,88 & 12,43 \\
\hline $\mathrm{Cr}_{2} \mathrm{O}_{3}$ & 0,09 & 0,02 & nd & 0,03 & nd & 0,02 & 0,06 & nd & 0,03 & 0,05 & nd & 0,14 & nd & 0,02 & 0,27 & 0,27 & 0,12 \\
\hline $\mathrm{MnO}$ & 0,45 & 0,46 & 0,34 & 0,50 & 0,44 & 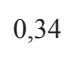 & 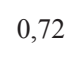 & 0,56 & 0 & 0 & 0,39 & , & $0, J 1$ & 0,30 & 0,08 & 0,11 & 0,36 \\
\hline $\mathrm{MgO}$ & 180 & 033 & 12,46 & 12,62 & 10,66 & 11,21 & 11,15 & 12,07 & 613 & 10,04 & 881 & 12,28 & 12,37 & 15,40 & 16,16 & 19,46 & 13,97 \\
\hline $\mathrm{CaO}$ & 1,29 & 10,89 & 11,19 & 11,58 & 11,61 & 11,52 & 11,15 & 10,95 & 10,74 & 11,41 & 10,85 & 11,04 & 11,6 & 10,58 & 11,21 & 11,41 & 11,43 \\
\hline $\mathrm{Na}_{2} \mathrm{O}$ & 0,06 & 1,25 & 1,03 & 0,89 & 0,54 & 0,96 & 0 & 0 & 0,97 & 0,83 & 0,95 & 0,95 & 0,77 & 0,84 & 13 & 0,35 & 0,75 \\
\hline $\mathrm{K}_{2} \mathrm{O}$ & nd & 1,03 & 0,44 & 0,84 & 010 & 0,66 & 1,08 & 063 & 0,98 & 0,79 & 0,56 & 0,18 & 0,11 & 0,27 & 0,58 & 0,06 & 0,25 \\
\hline $\mathrm{F}$ & 0,03 & 0,07 & 0,07 & 0,10 & 0,05 & nd & 0,16 & 0,04 & nd & 0,08 & 0,06 & nd & 0,11 & 0,08 & 0,09 & 0,04 & 0,13 \\
\hline $\mathrm{Cl}$ & 0,02 & 0,09 & 0,02 & 0,17 & 0,05 & nd & 0,04 & 0,23 & nd & nd & nd & 0,01 & 0,04 & 0,07 & nd & nd & 0,01 \\
\hline Total & 97,52 & 97,31 & 97,19 & 97,54 & 96,06 & 96,67 & 96,54 & 97,34 & 96,88 & 96,86 & 96,86 & 97,32 & 97,82 & 97,07 & 95,57 & 95,79 & 96,18 \\
\hline
\end{tabular}


Tabela 5 - Continuação.

\begin{tabular}{|c|c|c|c|c|c|c|c|c|c|c|c|c|c|c|c|c|c|}
\hline Amo & 11 & 11 & 1 & 1 & 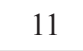 & 1 & 11 & 11 & 11 & 11 & 11 & 11 & 11 & 11 & 11 & 11 & 11 \\
\hline $\mathrm{SiO}_{2}$ & : & 48,22 & & 8,96 & 49,93 & 52,46 & 15- & & & 3,26 & & 48,76 & 51,29 & 4,04 & 0,39 & 5,95 & 7,32 \\
\hline $\mathrm{TiO}_{2}$ & 180 & 1,59 & 7 & 1,11 & 0,16 & 0,1 & 124 & 0 & 0,43 & 7 & 3,42 & 1 & 0 & 7 & 27 & 11 & nd \\
\hline $\mathrm{Al}_{2} \mathrm{O}_{3}$ & 007 & $0 x$ & 202 & 50 & 5 & 6 & 202 & 0 & 77 & 30 & & 5.77 & 508 & 12 & 02 & 03 & 1,03 \\
\hline $\mathrm{FeO}$ & 12,22 & 12,64 & 12,76 & 13,00 & 10,78 & 10,53 & 7,17 & 11,28 & 5,90 & 7,55 & 11,58 & 6,19 & 6,97 & 7,33 & 4,86 &, 50 & 2,03 \\
\hline $\mathrm{Cr}_{2} \mathrm{O}_{3}$ & nd & 0,04 & 04 & nd & nd & & 0,20 & 2 & ar & II & & 0,02 & 0,14 & 0,27 & 0,31 &, 02 & nd \\
\hline & 0,13 & 0,63 & & & נ, & & 0,0 & 0,2 & 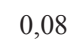 & 0,20 & & 0 , & 0,16 & 0,24 & 0,03 & 0,21 & 0,10 \\
\hline $\mathrm{MgO}$ & 12,29 & 13,77 & 7 & 13,4 & 15 & 17,03 & 15,83 & 17,25 & 19,21 & 17,47 & & 19,16 & 18,46 & 18,73 & 9,08 & 1,62 & 22,45 \\
\hline $\mathrm{CaO}$ & 10,66 & 11,16 & 10,65 & 11,69 & 11,33 & 10,34 & 12,22 & 9,13 & 11,43 & 11,67 & 10,4 & 10,5 & 11,72 & 11,26 & 12,12 & 12,19 & 12,85 \\
\hline $\mathrm{Na}_{2} \mathrm{O}$ & 161 & 089 & 2,06 & 0.78 & 088 & 04 & 085 & 036 & 086 & 075 & 241 & 243 & 0,67 & 032 & 036 & 0,27 & 0,16 \\
\hline $\mathrm{K}_{2} \mathrm{O}$ & 0,17 & 0,46 & 0,38 & 0,4 & & 0,04 & 0,13 & & II & 0,14 & & 0,33 & 0,28 & 0,05 & 0,11 & 0,02 & 0,15 \\
\hline $\mathrm{F}$ & & & 0,03 & & & , o J & ( & & & & & & &, 00 & (1) & tw & 0,09 \\
\hline $\mathrm{Cl}$ & 06 & pe & 0 & (2) & 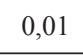 & 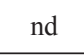 & 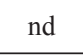 & م م & 0 & 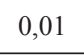 & 0,0 & 0,0 & 0,0 & 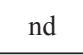 & 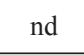 & 0,02 & nd \\
\hline Total &, 11 &, 51 & 02 & 60 &, 63 & 5,31 & 5,06 & 5,34 & 6,26 & 6,70 & 95 & 95, & 94, & 95,52 & 96,56 & 95,84 & 96,18 \\
\hline
\end{tabular}

superior a 0,3 . No litoral norte do Rio Grande do Sul, foram encontrados os dois tipos de epidotos em todas as amostras (Tab. 6). Os epidotos magmáticos podem provir dos granitóides subalcalinos e shoshoníticos do Batólito Pelotas, enquanto os demais, assinalam a presença de rochas metamórficas de fácies anfibolito ou de rochas hidrotermalizadas nas áreas fontes.

As zoisitas são minerais típicos de metamorfismo regional de grau médio em rochas de composição margosa, geralmente associada com granada, plagioclásios sódicos, biotita e hornblenda. Também podem ocorrer em eclogitos com hornblenda e alteração hidrotermal (Deer et al. 1981). A zoisita está presente ao longo do litoral norte, não sendo encontrada somente na amostra 10.

Granada As variações composicionais apresentadas pelas granadas podem ser utilizadas nos estudos de proveniência. Granadas de diferentes paragêneses ocupam diferentes campos composicionais (Wright 1938), em diagramas triangulares com $\mathrm{AE}$ (almandina + espessartina) - P (piropo) - GA (grossulária + andradita). Com base nos campos deste diagrama (Fig. 6), as granadas das amostras 10 e 11 (Tab. 7) seriam derivadas de granitos e pegmatitos, enquanto granadas de biotita xistos ou anfibolitos seriam encontradas nas amostras 8, 10 e 11.

As granadas ricas em almandina são em geral metamórficas de rochas quartzo-feldspáticas, as ricas em grossulária de rochas metassedimentares e as enriquecidas em espessartina são magmáticas de rochas graníticas meta a peraluminosas. Granadas deste último tipo são encontradas nas amostras 10 e 11, a almandina é encontrada principalmente nas amostras 8,10 e 11, e a grossulária, presente em todas amostras indica, mais uma vez, a importância dos metapelitos nas áreas fontes.

Turmalina A turmalina apresenta grandes variações composicionais e constitui-se assim em um importante indicador de proveniência (Henry \& Guidotti 1985). No

Tabela 6 - Composição química dos epidotos (\% em peso). EPI - epidoto; ZOI-zoizita (nd - não detectado).

\begin{tabular}{|c|c|c|c|c|c|c|c|c|c|c|c|c|c|c|c|}
\hline Amostras & 7 & 7 & 7 & 7 & 7 & 7 & 7 & 7 & 7 & 7 & 7 & 7 & 7 & 7 & 7 \\
\hline Mineral & EPI & EPI & EPI & EPI & ZOI & ZOI & ZOI & EPI & EPI & EPI & EPI & ZOI & EPI & EPI & EPI \\
\hline $\mathrm{SiO}_{2}$ & 38,37 & 38,57 & 39,15 & 39,34 & 39,5 & 39,73 & 39,52 & 38,16 & 39,21 & 38,24 & 38,01 & 39,43 & 38,49 & 38,31 & 38,13 \\
\hline $\mathrm{Al}_{2} \mathrm{O}_{3}$ & 23,09 & 24,56 & 27,28 & 28,45 & 29,25 & 30,35 & 29,53 & 24,93 & 28,53 & 22,00 & 24,29 & 29,46 & 24,85 & 24,15 & 22,65 \\
\hline $\mathrm{Fe}_{2} \mathrm{O}_{3} \mathrm{~T}$ & 12,35 & 10,73 & 7,05 & 6,16 & 5,21 & 3,95 & 4,84 & 9,49 & 6,39 & 14,57 & 12,44 & 5,58 & 11,78 & 11,57 & 13,48 \\
\hline $\mathrm{MgO}$ & 0,03 & 0,05 & 0,03 & 0,03 & 0,05 & 0,01 & 0,07 & 0,02 & 0,01 & 0,05 & 0,02 & 0,01 & 0,05 & 0,02 & 0,08 \\
\hline $\mathrm{CaO}$ & 23,06 & 23,05 & 23,62 & 23,49 & 23,99 & 23,75 & 23,76 & 23,21 & 23,92 & 22,94 & 23,19 & 23,35 & 22,63 & 23,08 & 23,1 \\
\hline $\mathrm{MnO}$ & 0,12 & 0,60 & 0,05 & 0,15 & 0,04 & 0,07 & 0,26 & 0,15 & 0,01 & 0,18 & 0,04 & 0,41 & 0,18 & 0,16 & 0,23 \\
\hline Total & 97,02 & 97,56 & 97,18 & 97,62 & 98,04 & 97,86 & 97,98 & 95,96 & 98,07 & 97,98 & 97,99 & 98,24 & 97,98 & 97,29 & 97,67 \\
\hline
\end{tabular}


Tabela 6 - Continuação

\begin{tabular}{l|ccccccccccccccc}
\hline Amostras & 7 & 7 & 7 & 7 & 7 & 7 & 7 & 7 & 7 & 7 & 7 & 7 & 7 & 8 & 8 \\
\hline Mineral & EPI & ZOI & ZOI & ZOI & ZOI & ZOI & ZOI & EPI & ZOI & EPI & EPI & EPI & ZOI & EPI & EPI \\
\hline $\mathrm{SiO}_{2}$ & 38,52 & 39,25 & 39,17 & 39,21 & 40,07 & 39,24 & 39,41 & 38,03 & 39,27 & 38,01 & 38,48 & 39,36 & 40,97 & 36,32 & 36,46 \\
$\mathrm{Al}_{2} \mathrm{O}_{3}$ & 26,23 & 30,28 & 29,46 & 29,27 & 20,33 & 30,05 & 29,84 & 27,44 & 29,38 & 24,72 & 25,45 & 26,77 & 33,14 & 21,16 & 21,27 \\
$\mathrm{Fe}_{2} \mathrm{O}_{3} \mathrm{~T}$ & 8,97 & 3,06 & 4,85 & 5,57 & 2,87 & 5,14 & 4,24 & 7,47 & 5,26 & 10,78 & 10,78 & 8,40 & 0,94 & 15,24 & 14,05 \\
$\mathrm{MgO}$ & 0,02 & 0,16 & 0,02 & 0,06 & 0,04 & 0,08 & 0,06 & 0,04 & 0,10 & 0,03 & 0,01 & 0,02 & 0,02 & 0,11 & 0,07 \\
$\mathrm{CaO}$ & 23,10 & 24,00 & 23,80 & 23,42 & 35,97 & 23,72 & 23,83 & 23,78 & 23,54 & 21,93 & 22,85 & 23,49 & 21,92 & 23,64 & 23,59 \\
$\mathrm{MnO}$ & 0,24 & 0,47 & 0,17 & 0,25 & 0,83 & 0,08 & 0,05 & 0,09 & 0,23 & 1,14 & 0,2 & 0,07 & 0,12 & 0,38 & 0,18 \\
\hline Total & 97,08 & 97,22 & 97,47 & 97,78 & 100,11 & 98,31 & 97,43 & 96,85 & 97,78 & 96,61 & 97,77 & 98,11 & 97,11 & 96,85 & 95,62 \\
\hline
\end{tabular}

\begin{tabular}{|c|c|c|c|c|c|c|c|c|c|c|c|c|c|c|c|}
\hline Amostras & 8 & 8 & 8 & 8 & 8 & 8 & 8 & 8 & 8 & 8 & 8 & 8 & 9 & 9 & 9 \\
\hline Mineral & $\mathrm{OI}$ & PI & EPI & EPI & EPI & EPI & ZOI & PI & PI & PI & PI & PI & PI & EPI & EPI \\
\hline $\mathrm{SiO}_{2}$ & 40,46 & 36,81 & 36,80 & 36,76 & 36,53 & 36,00 & 35,89 & 36,45 & 37,14 & 37,94 & 37,64 & 37,64 & 37,03 & 36,90 & 36,34 \\
\hline $\mathrm{Al}_{2} \mathrm{O}_{3}$ & 31,07 & 24,6 & 22,8 & 23,63 & 20,24 & 23 & 24,9 & 21, & 25 , & 20 & 2 & 8 & 2 & 22,66 & 19,80 \\
\hline $\mathrm{Fe}_{2} \mathrm{O}_{3} \mathrm{~T}$ & 0,93 & 10,43 & 12,74 & 12,00 & 14,53 & 10,55 & 5,21 & 14,01 & 9,88 & 14,46 & 9,76 & 8,59 & 14,31 & 13,21 & 16,83 \\
\hline $\mathrm{MgO}$ & nd & 0,07 & 0,01 & 0,05 & 0,15 & 0,01 & 1,43 & 0,04 & 0,05 & 0,13 & 0,03 & nd & 0,02 & 0,18 & 0,14 \\
\hline $\mathrm{CaO}$ & 22,51 & 23,21 & 23,48 & 22,62 & 22,28 & 22,94 & 23,34 & 22,99 & 23,74 & 22,67 & 23,79 & 23,72 & 23,77 & 23,97 & 23,67 \\
\hline $\mathrm{MnO}$ & 0,08 & 0,29 & 0,16 & 0,44 & 0,05 & 0,70 & 0,30 & 0,29 & 0,09 & 0,08 & 0,11 & 0,10 & 0,45 & 0,32 & 0,26 \\
\hline Total & 5,05 & 95,44 & 6,05 & 95,5 & 93,78 & 93,98 & 91,11 & 95,62 & 96,01 & 96,26 & 96,85 & 96,03 & 97,8 & 97,24 & 97,04 \\
\hline
\end{tabular}

\begin{tabular}{l|ccccccccccccccc}
\hline Amostras & 9 & 9 & 9 & 9 & 9 & 9 & 9 & 9 & 9 & 9 & 9 & 9 & 9 & 9 & 9 \\
\hline Mineral & EPI & EPI & ZOI & EPI & EPI & EPI & EPI & EPI & EPI & EPI & EPI & EPI & EPI & EPI & EPI \\
\hline $\mathrm{SiO}_{2}$ & 36,19 & 37,50 & 36,39 & 39,37 & 37,64 & 37,32 & 36,60 & 37,53 & 38,06 & 38,09 & 37,13 & 37,03 & 37,15 & 37,24 & 37,04 \\
$\mathrm{Al}_{2} \mathrm{O}_{3}$ & 18,83 & 24,51 & 22,30 & 26,19 & 25,41 & 22,45 & 23,25 & 24,34 & 25,74 & 25,60 & 22,82 & 22,57 & 22,46 & 22,77 & 21,68 \\
$\mathrm{Fe}_{2} \mathrm{O}_{3} \mathrm{~T}$ & 17,88 & 11,37 & 7,87 & 7,88 & 10,36 & 14,13 & 12,42 & 11,71 & 8,99 & 9,31 & 13,29 & 13,82 & 14,10 & 13,88 & 14,77 \\
$\mathrm{MgO}$ & 0,05 & 0,07 & 2,43 & 0,10 & 0,02 & 0,07 & 0,08 & 0,04 & 0,06 & 0,05 & 0,06 & 0,02 & 0,02 & 0,05 & 0,21 \\
$\mathrm{CaO}$ & 23,19 & 24,10 & 22,67 & 22,22 & 24,38 & 23,62 & 23,53 & 23,93 & 24,60 & 23,57 & 24,01 & 23,49 & 23,57 & 23,40 & 23,16 \\
$\mathrm{MnO}$ & 0,54 & 0,23 & 0,24 & 0,03 & 0,02 & 0,24 & 0,34 & 0,17 & 0,08 & 1,14 & 0,02 & 0,28 & 0,41 & 0,79 & 0,15 \\
\hline Total & 96,68 & 97,78 & 91,90 & 95,79 & 97,83 & 97,83 & 96,22 & 97,72 & 97,53 & 97,76 & 97,33 & 97,21 & 97,71 & 98,13 & 97,01 \\
\hline
\end{tabular}

\begin{tabular}{|c|c|c|c|c|c|c|c|c|c|c|c|c|c|c|c|}
\hline Amostras & 9 & 9 & 9 & 9 & 9 & 10 & 10 & 10 & 10 & 10 & 10 & 10 & 10 & 10 & 10 \\
\hline Mineral & EPI & EPI & EPI & EPI & EPI & EPI & EPI & EPI & EPI & EPI & EPI & EPI & EPI & EPI & EPI \\
\hline $\mathrm{SiO}_{2}$ & 37,43 & 36,26 & 37,14 & 36,99 & 36,61 & 37,48 & 37,41 & 38,43 & 38,32 & 38,29 & 38,40 & 37,90 & 37,64 & 37,88 & 38,18 \\
\hline $\mathrm{Al}_{2} \mathrm{O}_{3}$ & 22,43 & 20,86 & 22,59 & 22,34 & 21,79 & 20,59 & 21,43 & 23,04 & 24,46 & 25,90 & 22,32 & 22,53 & 23,28 & 22,91 & 23,55 \\
\hline $\mathrm{Fe}_{2} \mathrm{O}_{3} \mathrm{~T}$ & 13,84 & 15,16 & 13,97 & 14,35 & 13,74 & 17,17 & 15,42 & 13,63 & 12,95 & 10,90 & 13,60 & 14,21 & 13,05 & 13,96 & 13,02 \\
\hline $\mathrm{MgO}$ & 0,04 & 0,25 & 0,05 & 0,59 & 0,12 & 0,01 & 0,08 & 0,01 & 0,02 & 0,05 & 0,23 & 0,01 & 0,05 & 0,17 & nd \\
\hline $\mathrm{CaO}$ & 24,08 & 23,66 & 24,10 & 23,06 & 23,51 & 22,39 & 22,72 & 22,53 & 23,12 & 21,98 & 23,08 & 22,89 & 22,80 & 22,73 & 22,79 \\
\hline $\mathrm{MnO}$ & 0,12 & 0,10 & 0,11 & 0,40 & 0,12 & 0,12 & 0,09 & 0,19 & 0,13 & 0,75 & 0,04 & 0,16 & 0,11 & 0,41 & nd \\
\hline Total & 97,94 & 96,29 & 97,96 & 97,73 & 95,89 & 97,76 & 97,15 & 97,83 & 99,00 & 97,87 & 97,67 & 97,70 & 96,93 & 98,06 & 97,54 \\
\hline Amostras & 10 & 10 & 10 & 10 & 10 & 10 & 10 & 10 & 10 & 10 & 11 & 11 & 11 & 11 & 11 \\
\hline Mineral & EPI & EPI & EPI & EPI & EPI & EPI & EPI & EPI & EPI & EPI & EPI & EPI & EPI & EPI & EPI \\
\hline $\mathrm{SiO}_{2}$ & 36,78 & 37,94 & 38,01 & 38,42 & 36,80 & 37,37 & 38,17 & 38,14 & 37,75 & 38,08 & 37,81 & 37,39 & 38,13 & 38,74 & 37,48 \\
\hline $\mathrm{Al}_{2} \mathrm{O}_{3}$ & 23,21 & 20,96 & 22,21 & 25,17 & 20,86 & 24,84 & 24,30 & 25,82 & 25,64 & 25,07 & 23,13 & 22,60 & 13,34 & 21,72 & 22,12 \\
\hline $\mathrm{Fe}_{2} \mathrm{O}_{3} \mathrm{~T}$ & 14,41 & 16,01 & 14,30 & 10,40 & 15,93 & 10,58 & 12,42 & 10,17 & 10,41 & 11,03 & 13,32 & 13,73 & 13,35 & 15,01 & 14,67 \\
\hline $\mathrm{MgO}$ & 3,10 & 0,05 & 0,01 & 0,18 & nd & 0,03 & nd & 0,06 & 0,05 & 0,01 & nd & 0,01 & nd & 0,33 & 0,03 \\
\hline $\mathrm{CaO}$ & 19,88 & 23,06 & 23,14 & 22,78 & 22,43 & 23,15 & 22,99 & 22,57 & 23,03 & 23,18 & 22,85 & 22,63 & $22,, 73$ & 21,08 & 22,44 \\
\hline $\mathrm{MnO}$ & 0,27 & 0,17 & 0,18 & 0,21 & 0,13 & 0,18 & 0,22 & 1,03 & 0,38 & 0,16 & 0,18 & 0,41 & 0,20 & 0,08 & 0,52 \\
\hline Total & 97,65 & 98,19 & 97,85 & 97,16 & 96,15 & 96,15 & 98,10 & 97,79 & 97,26 & 97,53 & 97,29 & 96,77 & 87,75 & 96,96 & 97,26 \\
\hline
\end{tabular}


Tabela 6 - Continuação.

\begin{tabular}{|c|c|c|c|c|c|c|c|c|c|c|c|c|c|c|c|c|}
\hline $18 \mathrm{H}$ & 11 & 11 & 11 & 11 & 11 & 11 & 11 & 11 & 11 & 11 & 11 & 11 & 11 & 11 & 11 & 11 \\
\hline & & PI & & & EPI & & & EPI & EPI & & EPI & EPI & EPI & ZOI & $\mathrm{ZOI}$ & EPI \\
\hline $\mathrm{SiO}$ & 2 & 37,74 & 37,59 & 38,21 & 3011 & 37,82 & 37,50 & 38,31 & 18 & 38,24 & 19 & 7,91 & 8,36 & 3,94 & 8,94 & 7,88 \\
\hline & 2402 & 23,60 & te & 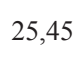 & 27,98 & & 19,33 & 8 & o & 7 & 26,09 & 23,45 & 63 & 28,53 & 3 & 2 \\
\hline & 12,02 & 15,05 & 18,19 & 12,15 & 1,48 & 10,11 & 11,94 & 3,54 & 14,00 & 9,11 & , & 11,00 & 9,19 & 5,0I & 5,07 & 2,95 \\
\hline & 0,01 & 0,02 & 0,04 & 001 & 0,01 & 0,02 & 0,01 & 0,07 & 0,04 & 0,32 & 0,05 & 0,03 & 0,01 & 0,06 & 0,06 & nd \\
\hline & 22,75 & 23,05 & 22,65 & & 23,7 & & 22,56 & 22,30 & 22,64 & 21,94 & 23,16 & & 22,96 & 23,53 & 23,53 & 22,59 \\
\hline & & 0,05 & & & 0,04 & & & & & 0,05 & 0,02 & 0,16 & 0,19 & 0,14 & 0,14 & 0,30 \\
\hline Total & 7,89 & 7,51 & 98,57 & 98,70 & 98,32 & 97,30 & 97,49 & 97,82 & 98,21 & 95,33 & 95,52 & 95,28 & 96,34 & 96,27 & 96,27 & 96,04 \\
\hline
\end{tabular}

\begin{tabular}{|c|c|c|c|c|c|c|c|c|c|c|c|c|c|c|c|c|}
\hline Amo & 11 & 11 & 11 & 11 & 11 & 11 & 11 & 11 & 11 & 11 & 11 & 11 & 11 & 11 & 11 & 11 \\
\hline $\mathrm{Min}$ & PI & EPI & EPI & $70 I$ & PI & $\mathrm{F}_{2}$ & PI & PI & EPI & $70 \mathrm{I}$ & EPI & PI & EPI & EPI & EPI & EPI \\
\hline $\mathrm{SiO}_{2}$ & 7,96 & 37,63 & 2704 & 39,18 & 37,32 & 37,65 & 39,29 & 37,54 & 37,90 & 38,47 & 37,27 & 37,53 & 37,69 & 38,18 & 36,69 & 37,91 \\
\hline $\mathrm{Al}_{2} \mathrm{O}_{3}$ & 22,74 & 21, & 23 , & 29 & 20, & 21 & 23 & 21,19 & 22,85 & 00 & 20,60 & 22,13 & 38 & 25,03 & 19,20 & 3,82 \\
\hline $\mathrm{Fe}_{2} \mathrm{O}_{3} \mathrm{~T}$ & 1 & 13 & 11 & 4 & 15 & 13,95 & 9,65 & 14,16 & 11,80 & 7,14 & 1 & 1 & 10,31 & 8,89 & 15,30 & 0,99 \\
\hline $\mathrm{MgO}$ & 0,02 & 0,02 & 0,04 & nd & nd & 0,01 & 0,03 & 0,06 & 0,11 & 0,05 & 0,01 & nd & 0,10 & 0,02 & 0,70 & 0,07 \\
\hline $\mathrm{CaO}$ & 22,93 & 22,14 & 22,46 & 23,60 & 22,92 & 22,82 & 20,10 & 22,39 & 22,86 & 23,16 & 22,01 & 22,31 & 21,49 & 22,38 & 21,55 & 22,23 \\
\hline $\mathrm{InO}$ & $\varepsilon$ & 0,41 & 0,15 & 0,12 & 0,07 & 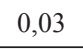 & 0,20 & , & 0 & $\mathrm{n}$ & 0 , & 0,3 & 1, & 0, & 0,08 & 0,27 \\
\hline Total & 5,62 & 95,83 & 96,29 & 97,00 & 96,32 & 96,17 & 92,27 & 95,46 & 95,69 & 95,82 & 96,19 & 96,33 & 95,10 & 95,00 & 93,52 & 95,29 \\
\hline
\end{tabular}

\begin{tabular}{l|cccccccccccccccc}
\hline Amostras & 11 & 11 & 11 & 11 & 11 & 11 & 11 & 11 & 11 & 11 & 11 & 11 & 11 & 11 & 11 & 11 \\
\hline Mineral & EPI & ZOI & EPI & EPI & EPI & ZOI & EPI & EPI & EPI & ZOI & ZOI & ZOI & ZOI & ZOI & EPI & ZOI \\
\hline $\mathrm{SiO} 2$ & 38,89 & 39,05 & 38,50 & 38,40 & 37,72 & 38,50 & 37,18 & 36,19 & 36,81 & 38,46 & 38,07 & 38,36 & 38,35 & 37,92 & 37,79 & 39,22 \\
$\mathrm{~A} 12 \mathrm{O} 3$ & 24,80 & 27,45 & 25,18 & 25,43 & 24,14 & 27,65 & 22,54 & 23,15 & 23,69 & 29,57 & 28,76 & 29,28 & 29,26 & 26,95 & 24,79 & 33,47 \\
$\mathrm{Fe} 2 \mathrm{O} 3 \mathrm{~T}$ & 9,78 & 6,32 & 11,40 & 10,3 & 12,24 & 6,40 & 13,51 & 11,90 & 12,54 & 5,11 & 5,62 & 4,82 & 5,05 & 8,00 & 10,58 & 0,38 \\
$\mathrm{MgO}$ & $\mathrm{nd}$ & 0,06 & 0,02 & 0,05 & 0,08 & 0,01 & 0,04 & 0,01 & 0,01 & 0,05 & 0,05 & 0,01 & 0,06 & 0,03 & 0,06 & 0,02 \\
$\mathrm{CaO}$ & 22,42 & 23,02 & 22,95 & 23,13 & 22,90 & 23,40 & 22,23 & 22,38 & 22,32 & 22,75 & 23,09 & 23,00 & 22,62 & 22,71 & 22,58 & 23,71 \\
$\mathrm{MnO}$ & 0,05 & 0,10 & 0,31 & 0,16 & 0,25 & 0,09 & 0,28 & 0,11 & 0,32 & 0,08 & 0,14 & 0,11 & 0,23 & 0,11 & 0,12 & nd \\
\hline Total & 95,94 & 96,00 & 98,36 & 97,47 & 97,33 & 96,05 & 95,78 & 93,74 & 95,69 & 96,02 & 95,73 & 95,58 & 95,57 & 95,72 & 95,92 & 96,8 \\
\hline
\end{tabular}

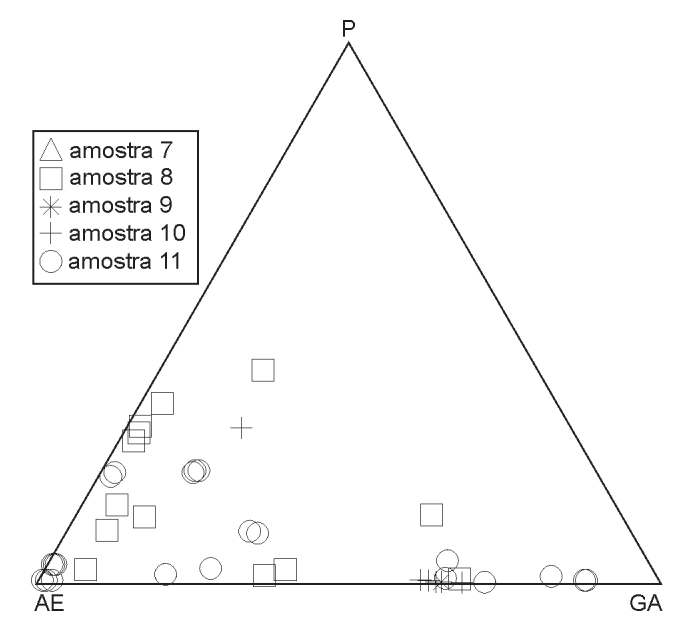

Figura 6 - Composições das granadas da fração granulométrica de areia muito fina das amostras analisadas. $P$ - piropo, $A E$ - almandina + espessartina, GA - grossulária + andradita. diagrama binário $\mathrm{FeO}$ x MgO, Morton (1991) mostra os campos das turmalinas mais comuns (dravita, uvita, shorlita e elbaíta). Dravita e uvita são de origem tipicamente metamórfica e metassomática, enquanto as shorlita e elbaíta são magmáticas de rochas graníticas ou pegmatíticas. As turmalinas identificadas, em todas as amostras (Tab. 8), são principalmente dravitas. Apenas nas amostras 7 e 11 foram também identificadas raras schorlitas (Fig. 7).

Os diagramas $\mathrm{Al}-\mathrm{Fe}_{\mathrm{T}}-\mathrm{Mg}$ e $\mathrm{Ca}-\mathrm{Fe}_{\mathrm{T}}-\mathrm{Mg}$ (Figs. 8 e 9) desenvolvidos por Henry \& Guidotti (1985) indicam que as turmalinas identificadas são principalmente derivadas de: (a) granitóides pobres em Li associados a pegmatitos e aplitos; (b) metapelitos pobres em $\mathrm{Ca}$ e metapsamitos e hidrotermalitos com quartzo e turmalina e (c) metapelitos ricos em Ca, metapsamitos e rochas cálcio silicatadas.

Zircão A composição química, principalmente elementos traços, de zircões detríticos do litoral norte do Rio Grande do Sul foi determinada e relacionada com suas potenciais fontes primárias por Barros et al. (submetido). 
Tabela 7 - Composição química das granadas (\% em peso). (nd - não detectado).

\begin{tabular}{|c|c|c|c|c|c|c|c|c|c|c|c|c|c|c|c|c|c|}
\hline Amostras & 7 & 7 & 7 & 7 & 7 & 7 & 7 & 7 & 7 & 7 & 7 & 7 & 7 & 7 & 7 & 7 & \\
\hline $\mathrm{SiO}_{2}$ & 37,73 & 36,87 & 38,5 & 36,37 & 39,42 & 39,99 & 39,11 & 37,58 & 36,43 & 37,62 & 36,54 & 38,04 & 38,00 & 36,60 & 36,85 & 36,97 & \\
\hline $\mathrm{TiO}_{2}$ & 0,11 & 0,07 & nd & 0,04 & 0,06 & 0,02 & 0,01 & 0,13 & 0,08 & 0,07 & 0,08 & 0,14 & 0,08 & 0,05 & 0,09 & 0,14 & \\
\hline $\mathrm{Al}_{2} \mathrm{O}_{3}$ & 21,2 & 19,88 & 21,42 & 20,6 & 20,43 & 20,31 & 20,75 & 24,96 & 19,99 & 20,26 & 20,63 & 21,33 & 21,7 & 20,40 & 20,19 & 21,13 & \\
\hline $\mathrm{Cr}_{2} \mathrm{O}_{3}$ & nd & nd & 0,04 & 0,10 & 0,05 & 0,01 & nd & 0,01 & nd & 0,02 & nd & 0,04 & nd & 0,02 & nd & 0,02 & \\
\hline $\mathrm{FeO}$ & 25,24 & 11,57 & 28,09 & 17,67 & 5,10 & 5,38 & 5,21 & 11,79 & 20,15 & 20,04 & 20,62 & 24,89 & 25,12 & 11,40 & 11,47 & 21,58 & \\
\hline $\mathrm{MnO}$ & 9,51 & 22,91 & 1,35 & 23,85 & 0,64 & 0,52 & 0,59 & 0,08 & 20,96 & 20,59 & 20,49 & 9,66 & 9,56 & 22,89 & 23,35 & 10,56 & \\
\hline $\mathrm{MgO}$ & 5,06 & 0,34 & 5,27 & 0,05 & 0,10 & 0,08 & 0,09 & 0,01 & 0,76 & 0,77 & 0,8 & 4,81 & 5,13 & 0,35 & 0,34 & 0,61 & \\
\hline $\mathrm{CaO}$ & 0,93 & 6,93 & 5,48 & 0,43 & 33,31 & 33,73 & 33,34 & 23,59 & 0,44 & 0,38 & 0,51 & 0,88 & 0,88 & 6,85 & 6,92 & 8,50 & \\
\hline $\mathrm{Na}_{2} \mathrm{O}$ & nd & 0,02 & 0,01 & 0,01 & 0,01 & nd & nd & 0,01 & 0,02 & nd & nd & nd & nd & nd & nd & 0,09 & \\
\hline Total & \begin{tabular}{|l|}
99,78 \\
\end{tabular} & 98,59 & 100,16 & 99,12 & 99,12 & 100,04 & 99,1 & 98,16 & 98,83 & 99,75 & 99,67 & 99,79 & 100,47 & 98,56 & 99,21 & 99,6 & \\
\hline Amostr & 7 & 7 & 7 & 7 & 7 & 7 & 7 & 7 & 7 & 8 & 8 & 8 & 8 & 8 & 9 & 9 & \\
\hline$\overline{\mathrm{SiO}_{2}}$ & 37,56 & 37,74 & 38,78 & 37,39 & 37,82 & 37,09 & 35,70 & 42,78 & 40,88 & 35,65 & 36,51 & 37,94 & 36,63 & 36,81 & 35,98 & 37,15 & \\
\hline $\mathrm{TiO}_{2}$ & 0,31 & 0,08 & 0,06 & 0,06 & 0,03 & nd & nd & 2,88 & 2,60 & 0,52 & 0,02 & 0,15 & 0,16 & nd & 0,03 & 0,25 & \\
\hline $\mathrm{Al}_{2} \mathrm{O}_{3}$ & 21,33 & 22,31 & 21,90 & 21,56 & 21,73 & 20,18 & 20,83 & 11,30 & 13,92 & 19,17 & 19,83 & 21,31 & 22,23 & 22,61 & 20,55 & 18,26 & \\
\hline $\mathrm{Cr}_{2} \mathrm{O}_{3}$ & 0,02 & 0,04 & 0,05 & 0,07 & 0,04 & nd & 0,03 & nd & 0,01 & 2,78 & 1,38 & $\mathrm{n}$ & 1,49 & 5,62 & 6,11 & nd & \\
\hline $\mathrm{FeO}$ & 20,43 & 28,03 & 28,81 & 22,20 & 22,80 & 18,04 & 17,70 & 12,15 & 11,00 & 15,91 & 15,62 & 24,88 & 12,74 & 12,26 & 21,72 & 23,41 & \\
\hline $\mathrm{MnO}$ & 10,57 & 1,37 & 1,45 & 4,73 & 4,86 & 23,12 & 23,77 & 0,30 & 0,14 & 0,05 & 0,09 & 0,59 & 0,25 & 1,09 & 16,27 & 2,73 & \\
\hline $\mathrm{MgO}$ & 0,62 & 5,36 & 5,28 & 2,25 & 2,34 & 0,09 & 0,07 & 13,69 & 13,88 & 0,04 & 0,01 & 7,67 & nd & 0,03 & 2,55 & 1,88 & \\
\hline $\mathrm{CaO}$ & 9,11 & 5,71 & 5,46 & 10,90 & 10,55 & 0,76 & 0,56 & 10,73 & 11,41 & 23,45 & 23,86 & 7,00 & 23,46 & 22,74 & 0,97 & 15,87 & \\
\hline $\mathrm{Na}_{2} \mathrm{O}$ & nd & nd & nd & nd & nd & nd & nd & 1,75 & 2,08 & nd & nd & 0,02 & nd & 0,01 & nd & 0,03 & \\
\hline Total & \begin{tabular}{|l|}
99,95 \\
\end{tabular} & 100,64 & 101,79 & 99,16 & 100,17 & 99,28 & 98,66 & 95,58 & 95,92 & 97,57 & 97,32 & 99,56 & 96,96 & 101,17 & 104,18 & 99,58 & \\
\hline Amos & 9 & 10 & P & 0 & 10 & 10 & 1 & 10 & 1 & 10 & 10 & 10 & 10 & 10 & 11 & 11 & 1 \\
\hline $\mathrm{SiO}_{2}$ & 36,78 & 37,35 & 38,65 & 38,77 & 36,61 & 36,85 & 38,11 & 38,44 & 39,21 & 36,57 & 38,21 & 38,28 & 37,65 & 36,78 & 39,41 & 37,18 & 36,09 \\
\hline $\mathrm{TiO}_{2}$ & 0,05 & 0,63 & 0,07 & 0,07 & 0,12 & 0,26 & 0,05 & 0,04 & nd & 0,30 & 0,20 & nd & nd & nd & 0,58 & 0,31 & 1,17 \\
\hline $\mathrm{Al}_{2} \mathrm{O}_{3}$ & 22,54 & 7,97 & 21,30 & 21,09 & 20,17 & 16,26 & 20,7 & 20,72 & 21,74 & 19,91 & 21,13 & 21,98 & 21,08 & 23,21 & 15,97 & 21,83 & 5,03 \\
\hline $\mathrm{Cr}_{2} \mathrm{O}_{3}$ & 5,55 & 0,01 & 0,02 & nd & 0,01 & nd & nd & 0,05 & 0,02 & nd & 0,04 & 0,03 & 0,03 & 0,08 & nd & nd & 0,01 \\
\hline $\mathrm{FeO}$ & 12,44 & 18,31 & 29,85 & 31,41 & 9,25 & 8,23 & 23,76 & 20,06 & 28,71 & 11,62 & 13,50 & 31,27 & 27,69 & 12,98 & 8,68 & 13,53 & 21,63 \\
\hline $\mathrm{MnO}$ & 0,20 & 0,95 & 2,19 & 1,44 & 29,17 & 22,31 & 10,62 & 6,40 & 0,93 & 23,83 & 13,93 & 0,8 & 9,37 & 0,27 & 0,45 & 0,30 & 0,20 \\
\hline $\mathrm{MgO}$ & nd & 0,20 & 7,57 & 6,77 & 0,54 & 0,39 & 3,13 & 0,60 & 8,72 & 3,57 & 13,79 & 7,17 & 2,46 & 3,10 & 0,28 & 0,97 & 0,24 \\
\hline $\mathrm{CaO}$ & 23,30 & 32,40 & 0,89 & 0,90 & 2,35 & 13,76 & 4,05 & 13,89 & 1,49 & 2,13 & 8,19 & 1,03 & 2,41 & 19,88 & 34,50 & 21,39 & 32,78 \\
\hline $\mathrm{Na}_{2} \mathrm{O}$ & nd & nd & nd & nd & nd & nd & nd & nd & nd & 0,03 & nd & nd & nd & 0,03 & nd & 0,02 & nd \\
\hline Total & 00,86 & 97,82 & 100,54 & 100,45 & 98,22 & 98,06 & 100,42 & 100,2 & 100,82 & 97,96 & 108,99 & 100,56 & 100,69 & 96,33 & 99,87 & 95,53 & 97,15 \\
\hline
\end{tabular}

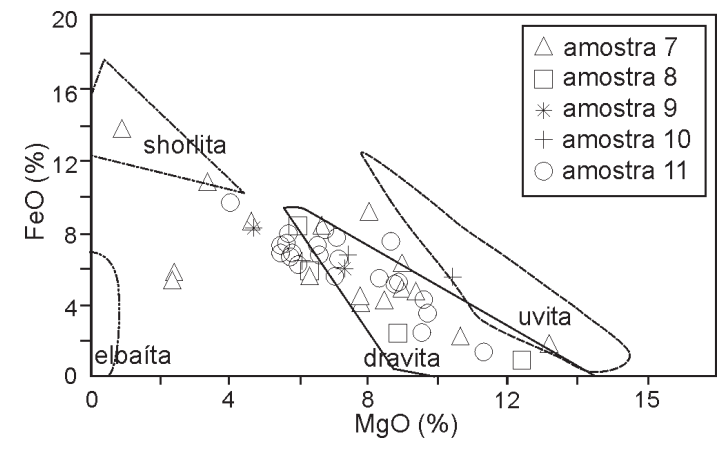

Figura 7 - Campo das composições das turmalinas (Morton 1991) da fração granulométrica de areia muito fina das amostras analisadas.
Concluem estes autores que o conteúdo de elementos traços do zircão detrítico é uma poderosa ferramenta em estudos de proveniência sedimentar. Com base principalmente nas razões $\mathrm{Th} / \mathrm{U}, \mathrm{Y} / \mathrm{Ho}, \mathrm{Nb} / \mathrm{Ta}$ e nos conteúdos de $\mathrm{Nb}$ e elementos terras raras, utilizando adicionalmente os parâmetros sugeridos por Belousova et al. (2002), esses autores concluíram que os zircões detríticos estudados provêm de associações de rochas graníticas subalcalinas a alcalinas do tipo A, com rochas máficas associadas e de associações metamórficas de alto grau. As variações composicionais dos grãos de zircão, nas amostras coletadas, são coerentes, de acordo com aqueles autores, com a hipótese de que eles provêm de áreas fontes continentais próximas, transportados provavelmente por correntes 
Tabela 8 - Composição química das turmalinas (\% em peso). (nd - não detectado).

\begin{tabular}{|c|c|c|c|c|c|c|c|c|c|c|c|c|c|c|c|c|c|}
\hline 11110 & 1 & 1 & 1 & 7 & 7 & 7 & 7 & 7 & 1 & 1 & 1 & 7 & 1 & 1 & 7 & 7 & 8 \\
\hline $\mathrm{O}_{2}$ & 59 & 7,36 & 6,56 & 5,51 & 5,89 & 6,97 & 7,52 & 7,01 & 7,93 & 7,75 & 6,65 & 36,35 & 6,84 & 7,27 & 7,03 & 5,53 & 5,30 \\
\hline $\mathrm{O}_{2}$ & 63 & nd & 74 & 60 & 0.33 & . & 38 & 30 & 01 & 02 & 1 & 1,09 & 67 & 8 &, 89 & 19 & .53 \\
\hline $1_{2} \mathrm{O}_{3}$ & 3503 & 3 & 3 & 34,21 & 29,62 & 5 & 8 & 6 & 6 & 30 & 53 & 66 & 87 & 15 & 45 & 35 & 3027 \\
\hline $\mathrm{eO}$ & 5,37 & 8,38 & 8,22 & 10,52 & 8,90 & 4,09 & 4,74 & 6,14 & 31 & 5,46 & 4,1 & 3,96 & 2,07 & 4,J0 & 1,61 & 13,54 & 6,68 \\
\hline $\mathrm{r}_{2} \mathrm{O}_{3}$ & 0.14 & nd & nd & nd & 0,01 & nd & 0,05 & 0,06 & 0.01 & 0,01 & 0,07 & 0,29 & 0,02 & 0,06 & nd & nd & 0,06 \\
\hline $\mathrm{InO}$ & 6 & 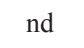 & nd & 0 & & 0,02 & & & & & & & 0,02 & & 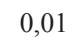 & 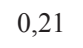 &, 17 \\
\hline $\mathrm{gO}$ & 6,33 & 4,64 & & , & & . & s & , & -2000 & & & 1,19 & 10,66 & 7, & 13,25 &, 90 & 7,44 \\
\hline $\mathrm{O}$ & 01 & 0,11 & 1,07 & 0,31 & 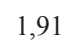 & , & 1,00 & 1,89 & 22,93 & 22,47 & 1,18 & 1,04 & 1,20 & 1,49 & 2,49 & 0,02 & 0,13 \\
\hline $\mathrm{a}_{2} \mathrm{O}$ & 27 & 1,57 & 1,64 & 1,61 & 15 & 1,52 & 1,8 & 1,28 & 0,03 & 0,05 & 1 & 1,68 & 1,8 & 1,69 & 1,37 & 1,43 & 2,61 \\
\hline${ }_{2} \mathrm{O}$ & 02 & 0,03 & & 0,06 & & 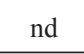 & 0,04 & 0,09 & 110 & 0,01 & 0,00 & 0,06 & 0,05 & 0,03 & 0,04 & 0,03 & 0,01 \\
\hline otal & 6,45 & 7,11 & 6,76 & 6,26 & 86,4 & 86,16 & 36,75 & 86,7 & 92,92 & 92,84 & 86,69 & 85,95 & 86,23 & 85,92 & 94,14 & 86,2 & 83,2 \\
\hline
\end{tabular}

\begin{tabular}{|c|c|c|c|c|c|c|c|c|c|c|c|c|c|c|c|c|c|}
\hline 10 & 8 & 8 & 9 & 9 & 0 & 10 & 10 & 10 & 11 & 11 & 11 & 11 & 11 & 11 & 11 & 11 & 11 \\
\hline $\mathrm{iO}_{2}$ & 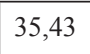 & 6,02 & 9 & 35,63 & 36,20 & 6 & 7 & 2 & 9 & 8 & 36,21 & 5 & 7 & 8 & 19 & 38 &, 03 \\
\hline $\mathrm{iO}_{2}$ & 0,60 & 0,22 & 2,26 & 0,81 & 0,79 & 0,25 & 0,56 & 1,36 & nd & 0,05 & 0,51 & 0,66 & 0,57 & 0,74 & 0,42 &, 79 & 1,61 \\
\hline $\mathrm{l}_{2} \mathrm{O}_{3}$ & 396 & 29,37 & 32,53 & 33,49 & 34,34 & 33,08 & 34,11 & 29,79 & 40,00 & 39,37 & 30,79 & 33,94 & 33,18 & 30,44 & 30,00 & 34,53 & 31,07 \\
\hline $\mathrm{OO}$ & 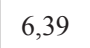 & נכ, &, 00 & 0,22 & 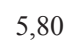 & 8,24 & 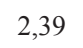 & ? & 25,02 & $20,1 J$ & , &, 12 & , & r & $\sqrt{0}, 0$ & 1,21 &, 17 \\
\hline${ }_{2} \mathrm{O}_{3}$ & nd & 3,2 & 1,1 & na & 0,0 & 0,01 & 0,5. & 0 & 0,02 & 0 & 0 & nd & 0,02 & 0, & 19 & 2 & 0,02 \\
\hline $\mathrm{nO}$ & 0,01 & nd & nd & 0,08 & nd & 0,01 & no & 0,03 & 0,38 & 0,40 & 0,09 & 0,08 & 0,04 & 0,09 & nd & nd & 0,02 \\
\hline $\mathrm{gO}$ & 10 & 10,45 & 700 & 70 & 63 & 508 & 887 & 1245 & 161 & 0,56 & 0 & 50 & 5,6 & 707 & 875 & 5.16 & 8,89 \\
\hline $\mathrm{aO}$ & 10 & 1,32 & 15 & & 0,99 & 02 & 1,31 & $2,0 J$ & nd & nd & & & 0,31 & & 0,00 & 0,כ0 & 2,13 \\
\hline $\mathrm{a}_{2} \mathrm{O}$ & 1,79 & 2,26 & 1,79 & 1,92 & 1,58 & 1,86 & 1,55 & 1,14 & 0,01 & nd & 1,67 & 1,73 & 1,86 & 2,18 & 2,16 & 1,70 & 1,21 \\
\hline${ }_{2} \mathrm{O}$ & 0,06 & 0,08 & 0,05 &, 05 & 006 & 0,01 & 0,06 & 0,06 & nd & nd & 0,03 & 0,04 & 0,02 & $\mathrm{nc}$ & d & 0,02 & nd \\
\hline otal & 5,12 & 88,52 & 88,66 & 85,22 & 86,16 & 86 & 85,84 & 85,72 & 91,03 & 90,73 & 84,05 & 84,62 & 84,92 & 85,13 & 83,79 & 86,22 & 86,15 \\
\hline
\end{tabular}

\begin{tabular}{l|cccccccccccccccc}
\hline Amostras & 11 & 11 & 11 & 11 & 11 & 11 & 11 & 11 & 11 & 11 & 11 & 11 & 11 & 11 & 11 & 11 \\
\hline $\mathrm{SiO}_{2}$ & 37,67 & 36,26 & 36,68 & 35,81 & 35,71 & 36,19 & 35,91 & 36,15 & 35,86 & 36,05 & 34,74 & 36,04 & 35,91 & 36,34 & 36,02 & 37,03 \\
$\mathrm{TiO}_{2}$ & 0,76 & 0,66 & 0,35 & 0,43 & 0,68 & 0,47 & 0,63 & 0,51 & 0,64 & 0,83 & 0,84 & 0,87 & 0,78 & 0,66 & 1,29 & 0,13 \\
$\mathrm{Al}_{2} \mathrm{O}_{3}$ & 33,34 & 33,86 & 29,87 & 32,72 & 35,04 & 31,73 & 34,9 & 33,18 & 33,54 & 34,36 & 34,54 & 34,67 & 31,51 & 32,44 & 29,10 & 31,44 \\
$\mathrm{FeO}$ & 9,57 & 7,89 & 7,38 & 7,26 & 6,82 & 8,11 & 6,76 & 6,42 & 6,63 & 6,60 & 6,84 & 5,48 & 4,17 & 3,46 & 1,33 & 2,42 \\
$\mathrm{Cr}_{2} \mathrm{O}_{3}$ & 0,02 & 0,04 & 0,06 & nd & nd & 0,05 & 0,12 & nd & 0,02 & 0,01 & 0,04 & 0,11 & nd & 0,04 & 0,19 & 0,86 \\
$\mathrm{MnO}$ & nd & 0,05 & 0,06 & 0,06 & nd & nd & nd & 0,02 & nd & 0,03 & nd & nd & 0,03 & nd & nd & nd \\
$\mathrm{MgO}$ & 4,02 & 5,67 & 8,68 & 6,53 & 5,45 & 6,74 & 5,81 & 7,13 & 6,60 & 5,77 & 5,81 & 7,01 & 9,61 & 9,69 & 11,34 & 9,55 \\
$\mathrm{CaO}$ & 0,06 & 0,21 & 0,72 & 1,01 & 0,58 & 0,59 & 0,45 & 0,70 & 0,82 & 0,14 & 0,84 & 0,94 & 1,80 & 1,58 & 2,85 & 0,75 \\
$\mathrm{Na}_{2} \mathrm{O}$ & 1,56 & 1,96 & 2,27 & 1,75 & 1,64 & 2,07 & 1,71 & 1,94 & 1,64 & 1,97 & 1,71 & 1,65 & 1,68 & 1,52 & 1,11 & 1,73 \\
$\mathrm{~K}_{2} \mathrm{O}$ & nd & 0,04 & 0,04 & nd & 0,03 & nd & 0,01 & 0,04 & 0,01 & 0,04 & 0,05 & 0,01 & 0,05 & nd & 0,05 & 0,03 \\
\hline Total & 87 & 86,64 & 86,11 & 85,57 & 85,95 & 85,95 & 86,3 & 86,09 & 85,76 & 85,8 & 85,41 & 86,78 & 85,54 & 85,73 & 83,28 & 83,94 \\
\hline
\end{tabular}

fluviais de pequeno porte durante fases de rebaixamento do nível do mar. A associação litológica de magmatismo granítico, subalcalino tipo A, e máfico com metamórficas de alto grau corresponde ao Batólito Pelotas (Philipp et al. 2002), situado imediatamente a oeste da planície costeira.

Rutilo O rutilo é um mineral estável em sistemas sedimentares e a sua presença indica fontes constituídas por metabasitos ou metapelitos da fácies anfibolito ou granulito (Zack et al. 2004). O rutilo esta presente ao longo de toda a área de estudo o que sugere a presença de rochas metamórficas de alto grau nas áreas fontes dos sedimentos estudados.

Estaurolita A estaurolita é um mineral tipicamente metamórfico, não sendo conhecida em rochas magmáticas (Clarke 1981). É relativamente estável durante os estágios iniciais de diagênese, mas sofre dissolução em altas temperaturas. Grãos de estaurolita são encontrados em todas 
as amostras, assinalando a presença de rochas metamórficas, possivelmente metapelitos, nas áreas fontes.

\section{A PROVENIÊNCIA DOS MINERAIS DETRÍTI-}

COS A composição dos piroxênios (provavelmente ígneos) encontrados nas amostras estudadas indica que os mesmos provêm dominantemente de fontes toleíticas pós-colisionais, descartando-se o magmatismo toleítico da Bacia do Paraná. Estes apresentam composições diferentes dos piroxênios encontrados nos sedimentos praiais estudados (Fig. 2).

Granitóides são importantes fontes de vários dos minerais detríticos identificados: (1) granitóides peraluminosos são indicados por schorlitas e granadas ricas em componente espessartita (Mn); (2) granitóides do tipo $\mathrm{A}$, isto é, de afinidade alcalina, são abundantes como fontes dos minerais detríticos e sua presença é indicada pelo zircão com mais alto teor de $\mathrm{Nb}$ e terras raras e por anfibólios com razões $\mathrm{FeOt} /(\mathrm{FeOt}+\mathrm{MgO})>0,9$; (3) granitóides subalcalinos médio a alto-K, ditos do tipo I, e shoshoníticos são as prováveis fontes principais de anfibólios com razões $\mathrm{FeOt} /(\mathrm{FeOt}+\mathrm{MgO})$ entre 0,7 e 0,9 , e de epidotos magmáticos, zircões e titanitas.

Rochas de alto grau metamórfico, das fácies anfibolito superior e granulito, tanto orto como paraderivadas são indicadas como importantes fontes dos sedimentos estudados pela presença de zircões com baixas razões $\mathrm{Th} / \mathrm{U}$, hiperstênio e diopsídio.

Apresença importante de metapelitos e metamargas de alto grau nas áreas fontes é indicada pela presença de estaurolita, rutilo, silicatos de alumíniocianita e silimanita, granadas ricas em componente almandina e grossulária, turmalinas enriquecidas em $\mathrm{Ca}$ e cumingtonita entre os minerais detríticos de todas amostras estudadas.

Turmalinas de provável origem hidrotermal pós-magmática, epidotos e anfibólios hidrotermais indicam a provável presença de hidrotermalitos entre as rochas fontes dos sedimentos estudados.

Associações litológicas semelhantes às previstas pela presença dos minerais detríticos nos sedimentos do litoral norte do Rio Grande do Sul são encontradas na porção nordeste e leste do Escudo Sul-rio-grandense. O Batólito de Pelotas (Philipp et al. 2002) é caracterizado nesta região por granitóides subalcalinos médio a alto-K, shoshoníticos e alcalinos ou do tipo A. Rochas máficas de afinidade toleítica à moderadamente alcalina ocorrem associadas a maior parte dos granitóides, tanto como diques, corpos concordantes ou enclaves máficos microgranulares. O Complexo Várzea do Capivarita, na mesma região é constituido por metapelitos e metamargas de alto grau metamórfico (Fernandes et al. 1990) e apresenta granadas ricas em componente almandina, silicatos aluminosos, e ortopiroxênios com En entre 62 e $65 \%$ conforme Silva et al. (2002). Nesta mesma região ocorrem diversos corpos de granitos e greisens com turmalinas, por vezes, associados com mineralizações de cassiterita e wolframita.

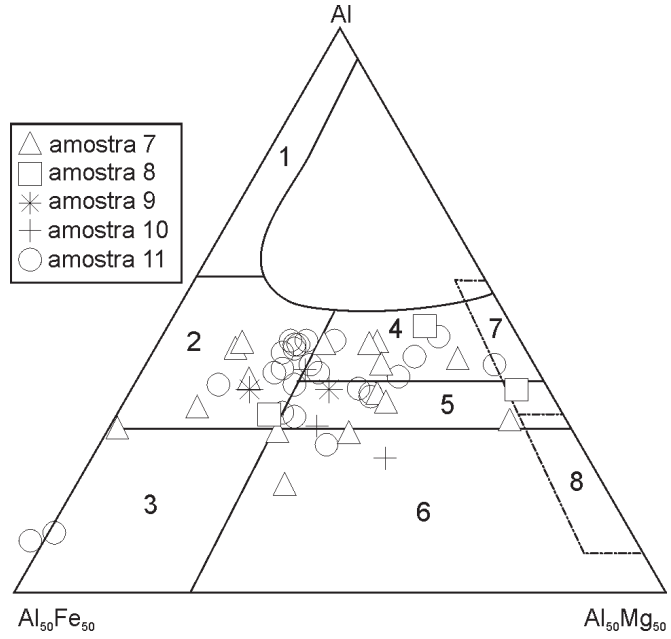

Figura 8 - Diagrama Al-Fe $e_{T}-M g$ para turmalinas (Henry \& Guidotti 1985) de diferentes tipos de rochas. (1) granitóides pegmatíticos e aplitos ricos em Li; (2) granitóides pobres em Li e associados a pegmatiticos e aplitos; (3) rochas quartzo turmalina ricas em $\mathrm{Fe}^{+3}$; (4) metapelitos co-existindo com fase saturada em Al; (5) metapelitos sem uma fase saturada em Al; (6) rochas quartzo turmalina ricas em $\mathrm{Fe}^{+3}$; rochas cálcio-silicatadas e metapelitos; (7) metaultramáfica baixo $\mathrm{Ca}$ e metassedimentos ricos em $\mathrm{Cr}$ e $\mathrm{V}$; (8) metacarbonatos e metapiroxenitos.

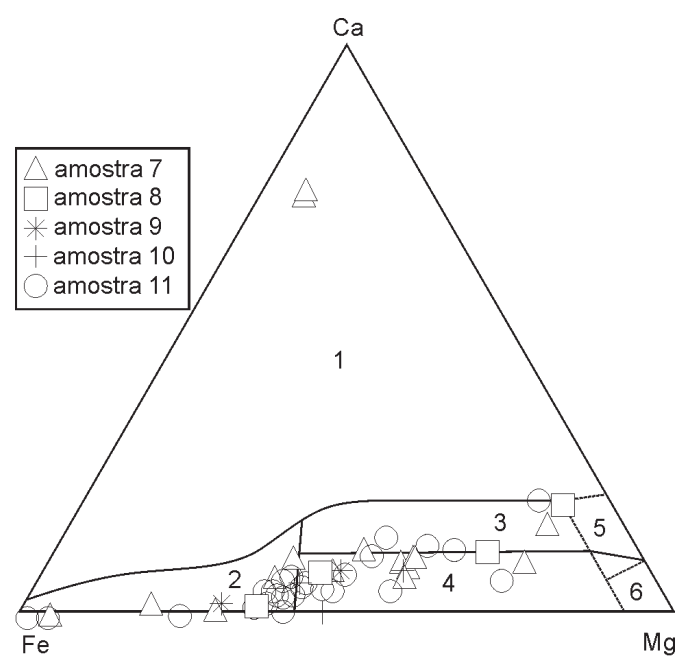

Figura 9 - Diagrama $\mathrm{Ca}-\mathrm{Fe}_{T}-\mathrm{Mg}$ para turmalinas (Henry \& Guidotti 1985) de diferentes tipos de rochas. (1) granitóides pegmatíticos e aplitos ricos em Li; (2) granitóides pobres em Li e associados a pegmatíticos e aplitos; (3) metapelitos ricos em Ca, metapsamitos e rochas cálciosilicatadas; (4) metapelitos pobres em Ca, metapsamitos e rochas quartzo turmalina; (5) metacarbonatos; (6) meta-ultramáfica. 
CONCLUSÕES A identificação das associações minerais presentes nas frações detríticas pesadas das areias praiais muito finas do litoral norte do estado do Rio Grande do Sul e principalmente a definição de suas composições químicas permitiram sugerir a área fonte desses sedimentos. A composição dos piroxênios indica fontes metamórficas de alto grau e rochas básicas relacionadas com fontes similares às de arcos magmáticos, como as do magmatismo póscolisional Neoproterozóico do sul do Brasil. Rochas metamórficas metapelíticas e margosas de fácies granulito são fontes importantes e tem sua participação indicada pela estaurolita, rutilo, silicatos de alumínio - cianita e silimanita, granadas ricas em componente almandina e grossulária, turmalinas enriquecidas em $\mathrm{Ca}$ e cumingtonita presentes em praticamente todas amostras estudadas. Granitóides do tipo A, semelhantes aos descritos na Suíte Encruzilhada do Sul (Philipp et al. 2002) são fontes também importantes, indicadas pela presença de zircões com alto teor de $\mathrm{Nb}$ e ETR e razões $\mathrm{Nb} / \mathrm{Ta}$ superiores a 20, e anfibólios com alta razão $\mathrm{Fe} / \mathrm{Mg}$. Granitóides peraluminosos semelhantes aos da Suíte Cordilheira tem sua presença nas áreas fontes indicadas por: granada rica em espessartina e turmalina rica em ferro, enquanto granitóides shoshoníticos e subalcalinos médio e alto-K, como os descritos por Philipp et al. (2002) no Batólito Pelotas tem sua participação sugerida pela presença de epidoto magmático, titanita, anfibólios cálcicos com razões $\mathrm{Fe} / \mathrm{Mg}$ moderadas e zircões com razões $\mathrm{Th} / \mathrm{U}$ de 0,3 a 0,5 e Nb/Ta entre 5 e 15 . Rochas hidrotermalizadas e ultramáficas são também constituintes das áreas fontes e tem sua presença apontada por turmalinas com $\mathrm{Li}$, actinolita e anfibólios magnesianos.

A distribuição relativamente uniforme dos minerais detríticos estudados em todas as amostras coletadas indica uma área fonte comum para os sedimentos do litoral norte, embora possa haver o predomínio local de fontes como por exemplo, a de rochas hidrotermalizadas na amostra sete.

Este estudo indicou que o extremo nordeste do Batólito Pelotas, constituido predominantemente pelas suites Encruzilhada do Sul, Cordilheira e greisens associados, Viamão e Dom Feliciano (Philipp et al. 2002) e pelo Complexo Várzea do Capivarita (Fernandes et al. 1990) é a principal área fonte dos sedimentos praiais do Litoral Norte do RS.

Agradecimentos Este projeto foi financiado pelo CNPq- edital universal, processo número 471867/2003-9 e pela bolsa de produtividade do segundo autor. Agradecemos ao prof. Silvio Vlach - coordenador do laboratório de microssonda do IG-USP- São Paulo - pela oportunidade de realizar parte das análises de minerais.

\section{Referências}

Abreu S.F. (ed.) 1973. Recursos Minerais do Brasil. Universidade de São Paulo, São Paulo, 320 p.

Ayup R.N.Z., Corrêa I.C.S., Tomazelli L.J., Dillenburg S.R. 2001. Dispersão e proveniência dos minerais pesados nos sedimentos de fundo da Plataforma Continental SulBrasileira, Uruguaia e Norte-Argentina. In: Cong. Assoc. Bras. Est. Quaternário, 8, Boletim de Resumos, p. 126.

Ayup R.N.Z., Corrêa I.C.S., Tomazelli L.J., Dillenburg S.R. 2002. Área fonte e dispersão dos minerais pesados nos sedimentos superficiais da plataforma continental norte do Atlântico Sul Ocidental. In: SBG, Cong. Bras. Geol., XLI, Anais, p. 121.

Barros C.E., Nardi L.V.S., Dillenburg S.R., Ayup R.N.Z., Jarvis K., Baitelli R. (no prelo) Detrital minerals of modern beach sediments in southern Brazil: a provenance study based on chemistry of zircon. Jour. Coas. Res. (Aceito, sem data de publicação).

Belousova E.A., Griffin W.L., O’Reilly S.Y., Fisher N.I. 2002. Igneous zircon: trace element composition as an indicator on source rock type. Contribution Mineral Petrology, 143:602-622.

Bitencourt M.F. \& Nardi L.V.S. 2000. Tectonic setting and sources of magmatism related to the Southern Brazilian Shear Belt. Rev. Bras. Geoc., 30:184-187.

Campos T.F., Neiva A.M., Nardi L.V.S., Pereira L.S., Bonzanini L.F., Petta R., Meyer F.M. 2005. The magmatic epidote and amphibole from the Rio Espinharas hybrid complex, northeastern Brazil. Pesq. Geoc., 30(2):41-56.

Clarke D.B. 1981. The mineralogy of peraluminous granites: a review. Canad. Mineral., 19:3-17.

Corrêa I.C.S., Ayup R.N.Z., Tomazelli L.J., Toldo E.E.Jr. 2001. Distribuição dos minerais pesados nos sedimentos de fundo da Plataforma Continental Sul-Brasileira, Uruguaia e Norte-Argentina. In: Cong. Assoc. Bras. Est. Quaternário, 8, Boletim de Resumos, p. 124.

Deer W.A., Howie R.A., Zussman J. (eds.) 1981. Minerais Constituintes das Rochas - Uma Introdução. Lisboa, Fundação Caloustre Gulbenkian, 576p.

Delaney P. 1965. Fisiografia e a Geologia de superfície da Planície Costeira do Rio Grande do Sul. Publicação Especial da Escola de Geologia/UFRGS, 6:1-105.

Dillenburg S.R., Tomazelli L.J., Barboza E.G. 2004. Barrier evolution and placer formation at Bujuru southern Brazil. Mar. Geol., 203:43-56.

Fernandes L.A.D., Tommasi A., Porcher, C.C. 1990. Esboço estrutural de parte do Batólito de Pelotas - região de Quitéria-Capivarita. Acta Geol. Leopol., 13:117-138.

Florisbal L.M., Nardi L.V.S., Bitencourt M.F., Betiollo LM. 2005. As rochas máficas da suíte pós-colisional Paulo Lopes: magmatismo básico e granítico cogenéticos de afinidade toleítica no sul do Brasil. Pesq. Geoc., 32(2):69-80.

Fontana P.D. 1990. Investigações geofísicas preliminares sobre o Cone de Rio Grande, Bacia de pelotas - Brasil. Acta Geol. Leopol., 13:161-170.

Gehrels G.E., Yin A., Wang X.F. 2003. Detrital-zircon geochronology of the northeastern Tibetan plateau. Geol. Soc. Amer. Bul., 115(7):881-896.

Henry D.J. \& Guidotti C.V. 1985. Tourmaline as a petrogenet- 
ic indicator mineral: an example from the staurolite-grade metapelites of NW Maine. Am. Mineral., 70:1-15.

Hoskin P.W.O. \& Schaltegger U. 2003. The composition of zircon and igneous and metamorphic petrogenesis. Rev. Mineral. Geoche., 53:27-62.

Le Bas M.J. 1962. The role of aluminium in igneous clinopyroxenes with relation to their parentage. Am. Jour. Sci., 260:267-288.

Leterrier J., Maury R.C., Thonon P., Girard D., Marchal M. 1982. Clinopyroxene composition as a method of identification of the magmatic affinities of paleo-volcanic series. Ear. Planet. Sci. Let., 59:139-154.

Loss E. \& Dehnhardt E.A. 1983. Concentração de areias negras ao longo da Mineralógica. Acta Geol. Leopol., 7(14):93-130.

Martins L.R.S. 1967. Aspectos texturais e deposicionais dos sedimentos praiais e eólicos da Planície Costeira do Rio Grande do Sul. Publicação Especial da Escola de Geologia/UFRGS, p. 131-155.

Martins da Silva M.A. 1979. Provenance of heavy minerals in beach sands, southeastern Brazil: from Rio Grande to Chui (Rio Grande do Sul State). Sed. Geol., 24(1-2):133148.

Morimoto N., Fabries J., Ferguson A.K., Ginzburg I.V., Ross M., Seifert F.A., Zussman J., Aoki K., Gottardi G. 1988. Nomenclature of pyroxenes. Am. Mineral., 73:11231133.

Morton A.C. 1984. Stability of detrital heavy minerals in Tertiary sandstones from the North Sea Basin. Clay Miner., 19:287-308.

Morton A.C. 1991. Geochemical studies of detrital heavy minerals and their application to provenance research. In: Morton A.C., Todd S.P., Haughton P.D.W. (eds.) Developments in Sedimentary Provenance Studies, UK, Geological Society Special Publication, 57:31-45.

Munaro P. 1994. Geologia e Mineralogia do Depósito de Minerais Pesados de Bojuru, RS. Dissertação de Mestrado, Instituto de Geociências, Universidade Federal do Rio Grande do Sul, 96 p.

Nardi L.V.S. 1991.Caracterização petrográfica e geoquímica dos granitos metaluminosos da associação alcalina: revisão. Pesq., 18(1):44-57.

Nisbet E.G. \& Pearce J.A. 1977. Clinopyroxene composition in mafic lavas from different tectonic settings. Cont. Mineral. Petrol., 63:149-160.

Philipp R.P., Machado R., Nardi L.V.S., Lafon J.M. 2002. O
Magmatismo Granítico Neoproterozóico do Batólito Pelotas no Sul do Brasil: Novos Dados e Revisão da Geocronologia Regional. Rev. Bras. Geoc., 32(2):277-290.

Pomerancblum M. \& Costa M.P.A. 1972. Integração de Informações sobre Minerais Pesados da Plataforma Continental Brasileira. In: Cong. Bras. Geol., 26, Anais, 2:179.

Rubatto D. 2002. Zircon trace element geochemistry: partitioning with garnet and the link between $\mathrm{U}-\mathrm{Pb}$ ages and metamorphism. Chem. Geol., 184:123-138.

Silva A.O.M., Porcher C.C., Fernandes L.A.D., Droop G. 2002. Termobarometria da Suíte Metamórfica Várzea do Capivarita (RS): Embasamento do Cinturão Dom Feliciano. Rev. Bras. Geoc., 32(4):419-432.

Tomazelli L.J. 1978. Minerais pesados da Plataforma Continental do Rio Grande do Sul. Acta Geol. Leopol., 2(5):103-135.

Tomazelli L.J., Villwock J.A., Dillenburg S.R., Bachi F.A., Dehnhardt B.A. 1998. Significance of present-day coastal erosion and marine transgression, Rio Grande do Sul, Southern Brazil. Anais Acad. Bras. Ciên., 70:221-229.

Viero A.P. \& Roisenberg A. 1992. Petrologia e geoquímica do Complexo Básico de Lomba Grande, RS. Pesq., 19(1):4154.

Villwock J.A., Loss E.L., Dehnhardt E.A., Tomazelli L.J., Hofmeister T. 1979. Concentraciones de Arenas Negras a lo largo de la costa do Rio Grande do Sul. Memórias Del Seminário sobre Ecologia Bentônica y Sedimentación de la plataforma continental Del Atlántico Sur. In: Oficina Regional de Ciencia y Tecnología de la UNESCO para América Latina y el Caribe, p. 405.

Villwock J.A., Tomazelli L.J., Loss E.L., Dehnhardt E.A., Horn Filho N.O., Bachi F.A, Dehnhardt B.A. 1986. Geology of the Rio Grande do Sul Coastal Province. Quat. South Am. Ant. Penin., 4:79-97.

Wright W.I. 1938. The composition and occurrence of garnets. Am. Mineral., 23:436-449.

Zack T., Eynatten V.H., Kronz A. 2004. Rutile geochemistry and its potential use in quantitative provenance studies. Sed. Geol., 17(1-4):37-58.

Zen E. \& Hammarstrom J. 1984. Magmatic epidote and its petrologic significance. Geology, 12:515-518.

Manuscrito AE 068/2006

Submetido em 08 de fevereiro de 2007 Aceito em 24 de junho de 2008 